\title{
Technology Roadmapping Using Text Mining: A Foresight Study for the Retail Industry
}

\author{
Sercan Ozcan ${ }^{1,2,3}$, Amir Homayounfard ${ }^{4}$, Christopher Simms ${ }^{5}$, Jahangir Wasim ${ }^{6}$ \\ ${ }^{1}$ Portsmouth Business School, University of Portsmouth, Richmond Building, Portland St, \\ Portsmouth PO1 3DE. \\ sercan.ozcan@port.ac.uk \\ ${ }^{2}$ Department of Engineering Management, Bahcesehir Universitesi, Istanbul, Turkey \\ ${ }^{3}$ National Research University Higher School of Economics, Moscow, Russia \\ ${ }^{4}$ Essex Business School, University of Essex, Wivenhoe Park, Colchester, Essex, CO4 3SQ. \\ ahomay@essex.ac.uk \\ ${ }^{5}$ Portsmouth Business School, University of Portsmouth, Richmond Building, Portland St, \\ Portsmouth PO1 3DE. \\ chris.simms@port.ac.uk \\ ${ }^{6}$ Aberdeen Business School, Robert Gordon University. Gathdee Road Aberdeen AB10 7QE. \\ J.wasim@rgu.ac.uk
}

\begin{abstract}
:
Technology roadmapping is a widely accepted method for offering industry foresight as it supports strategic innovation management, and identifies the potential application of emerging technologies. Whilst roadmapping applications have been implemented across different technologies and industries, prior studies have not addressed the potential application of emerging technologies in the retail industry. Furthermore, few studies have examined service-oriented technologies by a roadmapping method. Methodologically, there are limited roadmapping studies which implement both quantitative and qualitative approaches. Hence, our paper aims to offer a foresight for future technologies in the retailing industry using an integrated roadmapping method. To achieve this, we used a sequential method that consisted of both a text mining and an expert review process. Our results show clear directions for the future of emerging technologies, as the industry moves towards unmanned retail operations. We generate eight clusters of technologies and integrate them into a roadmapping model, illustrating their links to the market and business requirements. Our study has a number of implications and identifies potential bottlenecks between the integration of front and backend solutions for the future of unmanned retailing.
\end{abstract}

Keywords: Text Mining, Patent Analysis, Technology roadmapping, Foresight, Retail Technologies, Emerging Technologies. 


\section{Introduction}

The retail sector is facing an unprecedented level of change, with a growing diversity of technologies likely to disrupt the sector and provide an increasing array of opportunities and challenges for retailers [1]. Recent advances in technologies, such as robotics, computer vision, and artificial intellengece (AI), are blurring the boundaries between in-store and online retailing, enabling retailers to interact with consumers through multiple touchpoints and expose them to a dynamic blend of information [2]. New technologies are also automating internal operations resulting in improvements in efficiency, effectiveness, and cost [3].

A broad variety of new technologies, including smart grids, home management systems, selfservice checkouts, cloud-based platforms, and the Internet of things (IoT), affect customer experiences whilst offering efficiency and effectiveness to retailers' operational activities [4]. New technologies enable retailers to meet consumers' new requirements and further understand their needs, enabling them to provide personalised services, improved customer experiences, upselling order values, and focusing more heavily on their feedback to capture emerging trends [1], [5]. For example, in the grocery sector, online retailers such as Amazon and Ocado are changing consumer purchasing habits through increased convenience, while fast-fashion retailers such as H\&M, Asos, and Zara are exploiting social media to capture new trends [6]. However, many technologies fail to remain in the market for a long time, primarily due to the comparatively slow rate of diffusion and adoption of innovations within the industry [7], [8]. Innovation in the retail sector is influenced by a variety of factors in different technological domains. Therefore, understanding the future of technological domains within the sector remains challenging and significant to academics, technology adopters, and providers.

The existing literature lacks a detailed empirical analysis of the retail sector's critical technological domains and future technologies. Prior studies of retail technologies have either examined particular aspects of retail activities or confined their analysis to narrow 
technological domains, such as omnichannel, self-service, or AI [9-14]. Although Grewal et al. [1] provided an initial categorisation of technologies in the retail sector, their study lacked detailed empirical analysis and did not present a roadmap of future technologies. Technological foresight studies are of significance to practitioners and policymakers for future technological investments and decision making, and technology roadmapping is a well-recognised foresight tool to map technologies together with its relevant applications and market needs/problems [15]. Technology roadmapping helps with the exploration of linkages among products, services, processes in the long run. A technology roadmap is a multi-layered, time-dependent framework for firms to highlight a technology development strategy in a range of business areas [16]. They provide an effective way to forecast technology and thus set realistic goals [17]. Technology roadmapping allows firms to position themselves for the likely future scenarios and enable them to undertake relevant preparation, such as repositioning R\&D and collaborating with the relevant partners [18].

Technology roadmapping allows companies to select between different technology alternatives, considering the required market needs or problems [19]. The importance of roadmapping is further pronounced within increasingly turbulent contexts, such as retailing, where emerging technologies continuously impact activities, provide a means of scanning the environment, and enable understanding how different technologies will influence the future of the sector [15], [20]. This turbulence has increased since coronavirus, in which online retailers, for example, have had to respond to rapid changes in demand. However, prior literature on technology roadmapping has failed to address the retail sector, despite its fast-growing and changing competitive environment [21-23].

The retail industry is a highly complex and efficiency-oriented environment where technologies are expected to revolutionise future value creation and delivery. For this reason, it is vital to identify critical technologies and applications, considering different retail 
operations so that relevant actors can implement a long-term plan to develop, select and adopt appropriate technology alternatives. In this manner, technological development is crucial for firms to achieve sustainable competitive advantage [1]. This informs the research problem addressed in our study, which foresights the future of technological progress for the retail sector.

By developing a valid and reliable mixed-method approach incorporating both text mining, using patent data, and expert reviews, our study aims to examine retail-oriented technologies using large patent datasets to provide a rich analysis of the field. Our data analysis provides a map of existing contemporary technologies and also the future technologies for retail. To achieve that, the following objectives are proposed:

- To map and illustrate the clusters of technologies, their relationships, and domains in the retail industry;

- To establish a technological roadmap and foresight for the future of retailing environment considering near and far future;

- To provide future directions for the relevant stakeholders' technology strategy and planning development based on the technology roadmap (megatrend and likely scenarios) and wildcards (weak signals).

The findings of our paper provide two principal contributions to the literature. Firstly, we contribute to the stream of studies on technology forecasting [21], [22], [24], [25]. Through an analysis of empirical patent data, we present a comprehensive roadmap of the future technologies within the retail sector and describe the evolving influence of these technologies on retailer operations. In doing so, our findings also contribute to existing studies of key technologies in the retail sector [1], [12], [13]; by providing a categorisation of eight key technological domains through clustering analysis. Our second contribution is the development of a novel sequential roadmapping method. This method enables us to provide an extensive 
analysis of the diverse technologies within the retail sector, which technology providers outside the sector frequently develop. Hence, we provide a methodological contribution through the implementation of a mixed-method approach. This method integrated the text mining approach with expert opinions across a total of twelve stages. We also provide the search query that is developed specifically for the retail industry.

The structure of the paper is as follows. Firstly, we examine prior studies where retail technologies are addressed and attempts to foresight technologies, which are presented to establish our research's foundation. Secondly, we review text mining approaches in this area to see other attempts. Subsequently, we illustrate our patent-based text mining and roadmapping process. In the results section, we first illustrate our technological examination results based on the clustering analysis, and then implement our roadmapping model, demonstrating the future of retailing. Finally, we complete our study focusing on our contributions to the field with key implications for the relevant stakeholders.

\section{Literature review and relevance of the study}

Considering the growing importance of technologies in the retail sector, alongside the unprecedented levels of change it faces, reviewing prior research on foresight studies and those that examine technology's roles remains of critical importance. As such, the following sections literature concerning the importance of technologies, particularly in a retail context. These include studies focused on categorising technologies, foresight studies and those that benefited from roadmapping approaches in multiple contexts. This also further justifies the positioning of our paper. Our review of the existing literature consists of two key sections. Firstly, Section 2.1 reviews key literature examining retail technologies and prior foresight related studies. To construct this initial section of our literature review, keyword searches were conducted within Web of Science (WoS) and Google Scholar to generate a list of relevant contributions [26]. Our search terms in the keywords, abstracts or titles included the following terms: retail* AND 
technolog* AND (analys* OR categor* OR futur* OR predict* OR foresight OR roadmap*). This was supplemented with an additional detailed search within key retail-specific journals. Potentially pertinent articles identified from the references within the examined papers were also subsequently reviewed. Literature reviewing identified both the increasing importance of diverse technologies and the lack of a roadmapping study in the retail sector. This informed Section 2.2, which explores key studies of technology roadmapping.

\subsection{Retail technology and foresight studies}

The retail market is facing unprecedented levels of change. Advances in technology have lead to a proliferation of new products and services while changing how retailers undertake their activities [1], [14]. The incorporation of technologies in different forms can impact the key dimensions of retail activities [27]. New combinations of technologies allow firms to undertake critical activities in new ways that lower the use of resources and the cost of operations [14], [28]. Implementing new technologies provides the opportunity to increasingly automate internal operations, resulting in improvements in efficiency, effectiveness, and cost reductions [29]. Recent technological advances in mobile computing and augmented reality are blurring the boundaries between in-store and online retailing, enabling retailers to interact with consumers through multiple channels, exposing them to vibrant information [13], [30], [31]. The diversity and rapid pace of digital technologies introduced presents retailers with ongoing questions over which technologies to adopt [2], [32]. They face increasing challenges in keeping up with the rate of technological innovations being launched into the market, while technology providers face relatively low rates of adoption and diffusion, which results in many technologies failing to achieve market success [27], [33]. This creates a need to examine the importance of technological domains and major future challenges presented to the retail sector 
[31]. Moreover, the literature lacks a systematic analysis of technologies within the retail sector and fails to present a comprehensive roadmapping analysis [1], [14].

Several studies have provided initial insights into the increasing influence of technologies and the retail sector's changing face, such as Von Briel [14], who explored the impacts of technologies on the future of omnichannel retailing within the next decade. Grewal et al. [1] recently suggested five broad areas in which technology development is enabling critical improvements: i) decision-making technologies, ii) visual displays and merchandising, iii) improved engagement and consumption, iv) big data collection and exploitation, and v) analytics and profitability. Their research lacked a detailed empirical analysis but laid a theoretical foundation for future studies exploring the diversity of technological advances.

Other studies have also addressed specific technological domains. Shankar [13] explored the diversity of AI-enabled retail activities. This research highlighted that retail activities benefit from AI, based on the analysis of four broad types of data: numeric data, text data, voice data, and visual/image/video data. Lee [10] highlighted that robots and intelligent agents are automated technologies that provide superior efficiency and reduce front-end or backend operating employees. Also, big data analytics, such as text analytics, machine learning, predictive analytics, data mining, and natural language processing, enable retailers to analyse large data sets and explore hidden customer preferences for a better forecast [34], [35].

Table 1 summarises the key literature that categorises retail technologies, identifying the lack of a comprehensive empirical analysis. To compile Table 1, we selected the retail studies that categorised the relevant technologies. Accordingly, the present study analyses the key technological domains that impact the present and future of retail activities. In doing so, we aim to understand how different groups of technologies impact products, service, and process at the front and backend of retail operations. This will also lead to an effective alignment of retailers' strategic objectives with related technologies. Despite these contributions, limited, if 
any, forecasting studies have highlighted how technology in different forms can impact the digital economy in general, and the retail sector in particular.

Table 1: Summary of the key literature on categorisation of technologies in retail

\begin{tabular}{lll}
\hline Reference & Method & Categories for future of retailing \\
\hline $\begin{array}{l}\text { Grewal } \text { et al. } \\
\text { [36] }\end{array}$ & Conceptual & $\begin{array}{l}\text { Future retail can create value based on 1) store factors, 2) service } \\
\text { factors, 3) merchandise, 4) price, 5) supply chain, and 6) } \\
\text { technology. }\end{array}$ \\
$\begin{array}{l}\text { Pantano and } \\
\text { Timmermans }\end{array}$ & Conceptual & $\begin{array}{l}\text { Retail is facing challenges from 1) need of ad-hoc capabilities, 2) } \\
\text { changes in knowledge management, 3) creation of smart } \\
\text { [37] }\end{array}$ \\
partnership, 4) changes in service access, 5) changes in a \\
salesperson, and 6) changes in consumption.
\end{tabular}

Grewal et al. [1] Conceptual Key areas of future success in retail: 1) technology and tools to facilitate decision-making, 2) visual display and merchandise offer decisions, 3) consumption and engagement, 4) big data challenge and usage, and 5) analytics and profitability.

Kumar et al. Empirical Technologies can impact five levels as 1) market level, 2) firm[12] level, 3) store level, and 4) customer level.

Roy et al. [5] Empirical Impact of smart customer experience on 1) smart technology, 2) customer, and 3) retailer-level outcomes.

Willems et al. Empirical Clusters of retail technologies: 1) product augmentation, 2) retail [27] environment, 3) smart retail furniture, 4) payment, 5) context-aware data pool, 6) product-finding, 7) personal product assistant, 8) personal decision support systems, 9) price comparison technologies, and 10) enabling.

Shankar [13] Discussion Retailers benefit from Artificial Intelligence (AI) technologies: 1) anticipating mobile shopper behaviour, 2) personalisation and recommendation systems, 3) sales/customer relationship management, 4) in-store customer experience management, 5) customer service and payment management, 6) media optimisation, 7) inventory optimisation, 8) logistics, transportation, and delivery management, and 9) store cleaning and layout management.

von Briel [14] Empirical Future competition in retail is based on 1) holistic customer experience, 2) development of human capabilities and changes in organisation mindset, 3) the importance of physical stores, and 4) importance of operational productivity.

\subsection{Roadmapping models and studies}

Technology roadmapping is one of many available foresight tools. However, it is one of the best methods for technology-specific planning, which links well to companies' overall strategic planning. Roadmapping dates back two decades [38], and remains a widely used method to integrate different levels such as technology, applications, and market levels across timelines 
[15], [22], [24], [39]. Roadmaps help support firm decision making on research and innovation, and they can be used to foresee potential technological futures and identify key milestones.

To map all roadmapping literature and examine its applications, Fig. 1 is created by retrieving 445 articles and conference proceedings from WoS using tech mining [40] and Scientometrics [41]. To generate this figure, we used roadmapping terms in the search results and limited results to business and management related studies, academic articles and conference proceedings using the WoS filters. 445 articles were retrieved and imported into VantagePoint to clean data using functions such as duplicate removals. UCINET software calculated centrality measures, and VOSviewer is used to present a heatmap for the roadmapping field, identifying the key industries, technologies, or purposes for which roadmapping has been used. For instance, roadmapping method has extensively been implemented within energy [42-44], semiconductors fields [45-47], and IoT [39], [48], [49]. Service sectors [50], and in particular the retail sector, have received limited attention. Lee et al. [51] integrated the roadmapping process for services, devices, and technologies to manage $R \& D$ in smart cities. They implemented Quality Function Deployment to establish interconnections between services, devices, and technologies. Using a similar approach, Geum et al. [52] developed an integrated model for a product-service integrated roadmap. These authors agree that there are limitations in service-oriented roadmapping models regarding suitable approaches and illustrative cases. Despite these contributions, the literature lacks a retail-specific roadmapping study. As shown in Fig. 1, roadmapping has been used for products [24], [53], technology strategy [22], [54], foresight and forecasting [55], competition analysis and business planning [20], [24], and technology exploitation and competency analysis [56]. Ilevbare et al. [57] integrated the roadmapping approach with risk assessments, focusing on technological uncertainties in the application of such models. Recently, the roadmapping approaches appear to be targeted towards business model development and planning [58]. 
Fig. 1 also shows data sources for roadmapping studies, identifying the use ofacademic publications [59], patents [22], [60], product manuals [23], expert views [51], and survey [61] as the primary data sources. For example, approaches including Delphi [51], interview analysis [61], bibliometrics [59], and text mining [62] are some of the quantitative and qualitative methods that are implemented. On different roadmapping application levels, roadmapping is used for technology [54], organisation [39], [63], industry [24], [42], and national levels [60]. 


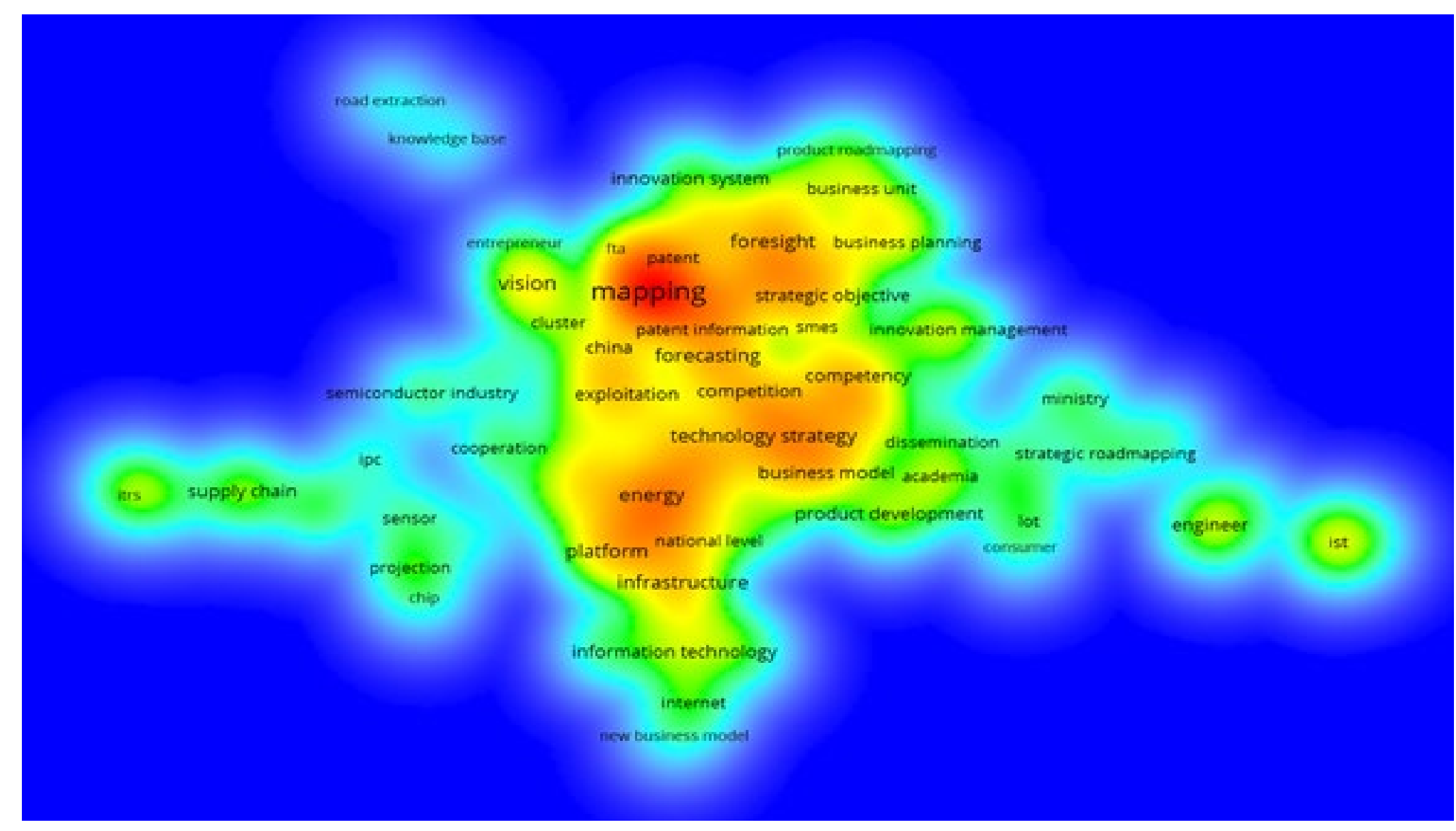

Figure 1. Summary of roadmapping literature and its application 
A summary of the key literature on different roadmapping applications is shown in Table 2 . Based on this result, a roadmapping approach can be selected according to the needs of the study. Caetano and Amaral [64] classified technology roadmapping literature as technology push and market pull. In comparison, our classification (Table 2), consists of four different conditions and 20 categories. The present study attempts an industry level, strategy, technology push, and foresight-based study, such studies remain limited [64]. Our study uses a mixedmethod text mining approach on patent documents and interim qualitative reviews assessments.

Table 2: Roadmapping classification by levels, purpose, and methodology

\begin{tabular}{ll}
\hline $\begin{array}{l}\text { Roadmapping types by different } \\
\text { conditions }\end{array}$ & Categories \\
\hline Roadmapping levels & Technology [22], [54] \\
& Organisation [39], [63] \\
& Industry [24], [42] \\
& National [60] \\
& Product roadmapping [53] \\
Technology strategy [54] & Foresight and forecasting [55] \\
Roadmapping purpose & Competition analysis and business planning [20], [24] \\
& Technology exploitation and competency analysis [56] \\
& Business model development and planning [58] \\
& Academic publications [59] \\
& Patents [22], [60] \\
& Product manuals [23] \\
Expert views [51] & Survey [61] \\
Roadmapping data sources & Delphi [51] \\
& Interview analysis [61] \\
Bibliometrics [59] & Text mining [39], [62] \\
Mixed method [59]
\end{tabular}

In general, considering the roadmapping process, there are three major layers needed to be established. These are technology/competencies, product/service, and business/market layers [22], [65], [66]. Fig. 2 shows from bottom to top, that these different layers are interconnected, technology leading to products/services, and those having business/market-oriented purposes. This method allows organisations, strategists, and policymakers to align resources to technologies to develop new products and services, fulfilling contemporary business operations and market requirements. 


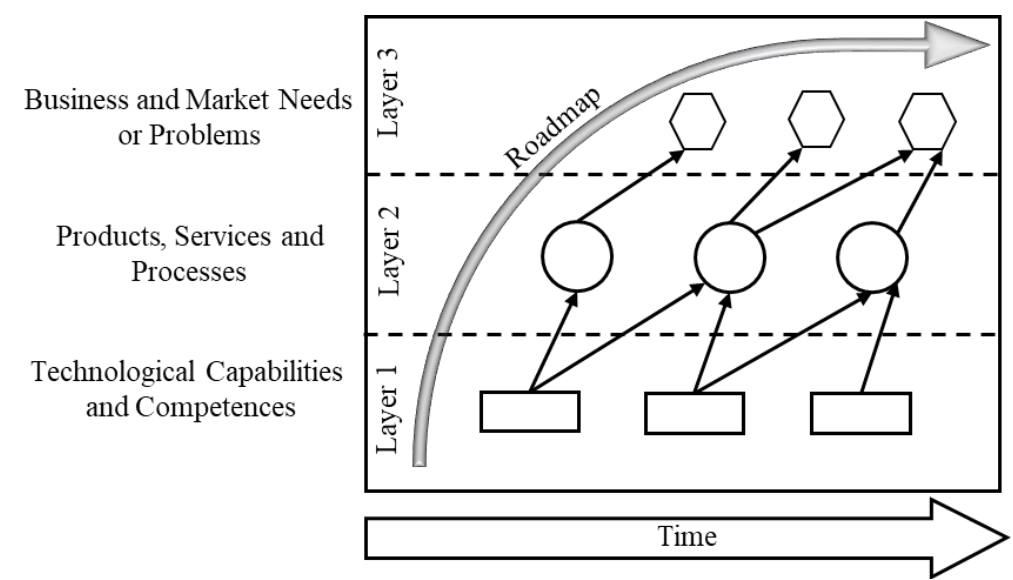

Figure 2 General roadmapping model, modified from Carvalho et al. [65] and Fenwick et al. [66]

There are different processes highlighted in Table 3 to implement technology roadmapping. Following these key studies, the first stage is the planning and preliminary activity to decide the aim, the scope and timeline of a roadmap. This is also to be prepared with the managerial setting to start with the roadmapping process. In the following steps, the differences are evident in the use of workshops, iterations, and analyses. However, each utilises workshops designed to collect information based on different layers or the roadmap. Finally, the roadmap is designed and prepared to be communicated to various stakeholders. The comparison section of Table 3 shows that expert opinion and patent-based approaches each possess their own advantages. A mixed-method approach most appropriate because it minimises each process weakness of roadmapping. We also benefit from all four studies and use the suggested steps in our mixed-method approach, where both patent data and expert opinion are utilised. 
Table 3: Reviewed studies for roadmapping process

\begin{tabular}{|c|c|c|c|}
\hline Amer and Daim [42] & Jeong and Yoon [22] & Phaal et al. [15] & Wells et al. [67] \\
\hline $\begin{array}{l}\text { Preliminary activity (provide } \\
\text { leadership/sponsorship, define } \\
\text { the scope and boundaries for } \\
\text { the technology roadmap) }\end{array}$ & $\begin{array}{l}\text { Planning (long term } \\
\text { strategy for improving } \\
\text { efficiency and technology } \\
\text { development) }\end{array}$ & $\begin{array}{l}\text { Planning (scope, organisational } \\
\text { goals, available information, } \\
\text { and resources) }\end{array}$ & $\begin{array}{l}\text { Planning (decision on scope, time } \\
\text { horizon and liaison between the } \\
\text { "roadmap owner" and a "process } \\
\text { facilitator") }\end{array}$ \\
\hline
\end{tabular}

Tech roadmap development (Identify the critical system requirements and their targets, specify the major technology areas, specify the technology drivers and their targets, identify technology alternatives and their timelines, recommend the technology alternatives that should be pursued, create the technology roadmap report)

Follow-up activity (Critique and validate the roadmap, develop an implementation plan)

Technology roadmap development (develop the ontology of technology, collect patent and generate keyword vector, group and classify patents)

Analyse patterns of patent development. Patent

roadmapping and patent planning using the technology layer composed of the technology roadmap
Roadmapping workshop/s (market, product, technology, roadmapping, and customised workshops)

Workshop 1 (agree on focus, populate TRM, first-cut roadmap, brainstorming and grouping techniques to identify and structure the elements)

Roll-out (application, support, maintaining and extending the process)
The research and validation (expert input, participant ownership, personal' TRM, examining the map content and its key messages, collecting and validating data generated in the first workshop, address key knowledge gaps). Workshop 2 (Review first cut TRM, generate links, decide outputs, extra information from the research stage and linked roadmap)
Comparison

Planning or preliminary activity is apparent in all roadmapping processes where the scope needs to be defined for the project. However, there are some differences Amer and Daim [60] mentioned leadership/sponsorship requirements, Jeong and Yoon [20] detailed integration of the roadmapping model into the longterm strategy, Phaal et al. [17] also mentioned integration to the organisational long term goals but also explained the importance of early assessment of the available information and resources. In addition to others, Well et al. [84] suggest setting the time

horizon for the roadmapping project and assigning relevant roles to develop the model at this stage.

There are differences between TRM implementation. This is mainly due to the data source. If expert opinion will be used as the main source of the roadmapping process then the approach of Amer and Daim [60], Phaal et al. [17] and Wells et al. [84] are more suitable. Jeong and Yoon [20] has a more suitable approach for quantitative and patent-based roadmap development.

However, all studies are relevant for mixed method approaches where quantitative data needs to be merged with the qualitative data.

After the roadmap is developed, there is a great variance between suggested processes. One significant aspect is to establish a step in the process where results are critiqued with the support of experts [17, 60, 84]. Jeong and Yoon [20] do not adopt this step and it appears to be missing a significant validation step. Follow up activities are also suggested where the roadmapping outputs can be implemented and this step is apparent in qualitative approaches. 
Context-specific studies are also examined, in addition to reviewing the roadmapping studies from an application, purpose and process perspective. Some service-oriented studies such as Wells et al. [67] apply a roadmapping model for the Royal Mail company. Whereas, Geum et al. [52] and Lee et al. [51] integrated product and service-based roadmapping efforts. Li [39] uses US patent data from 1993 to 2005 to illustrate Cisco's technological roadmap and its ecosystem. Few service-oriented studies are evident [51], [52], [67] and specifically a roadmapping study of the retail sector is lacking.

The preceding review has identified the practical gaps and methodological weaknesses in the existing literature. Quantitative studies where patent or scientific literature is used for roadmapping, and qualitative roadmapping studies like the Delphi method of systematic collection of expert opinion reaching a collective foresight, are both evident. However, few mixed-methods roadmapping studies are evident, such as Li et al. [59]. Hence our study addresses two gaps. Firstly, our review revealed a lack of foresight studies focused on retail technologies. Secondly, we identified a lack of a systematic categorisation of retail technologies into clusters and segments.

Existing literature predominantly focuses on classifying existing retail technologies with a limited specification of their future impact [1], [14], [27]. Despite the growing number of studies using patent and text mining techniques, research utilising large patent datasets to explore the diverse range of technologies in services sectors broadly and retail sector specifically, are limited. Our literature analysis revealed only one study focused on retail technologies using large patent datasets [68]. Their study utilised a similar quantitative and text-based methodology to examine selected patents. However, the data selection process was manual, with no explicit search query and limited technology-oriented analysis. Furthermore, the research did not examine the future of retail technologies, its inter-relationships, and trends with advanced data visualisation techniques. Foresight literature reveals few studies using 
patent data with a mixed-method approach, while text mining-based roadmapping studies are even fewer.

\section{Research method and design}

Our study implements sequential mixed-methods, where patent-based quantitative and expert opinion based qualitative methods are combined. The steps of the mixed method are designed according to the roadmapping process. The sequential mixed method approach was initiated with the quantitative text mining steps. This was followed by qualitative assessments using twelve retail experts as key informants (see Appendix A). Patent documents are large scale data, to make this manageable, we utilised text mining, which also enabled us to identify the key clusters of technologies within the dataset. The use of key informants improves the research's validity and reliability as they describe their patterns of execution and provide an observed empirical experience [69]. Fig. 3 summarises the twelve quantitative and qualitative stages of our research. The qualitative stages consist of both authors' and experts' involvement, and the quantitative stages are based on the text mining method. The methodological process is discussed in two parts as qualitative and quantitative steps in the following sections. Both stages are designed according to the roadmapping process.

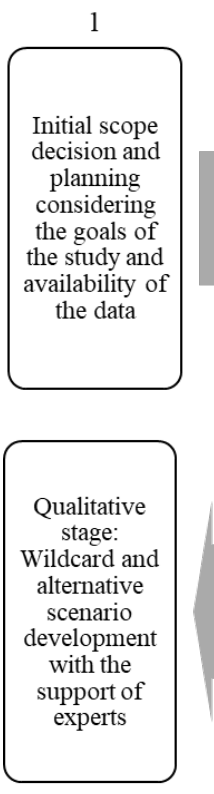

12

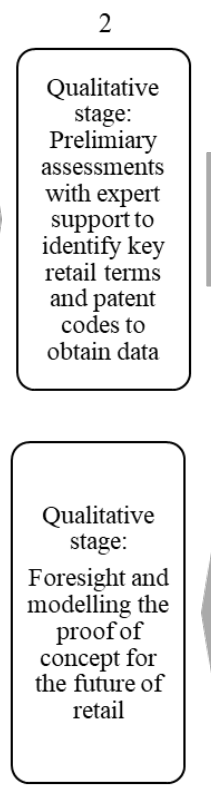

11
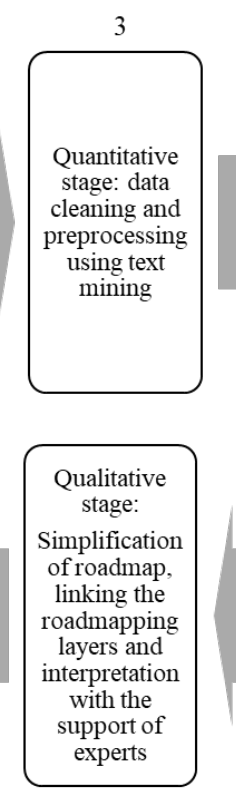

10
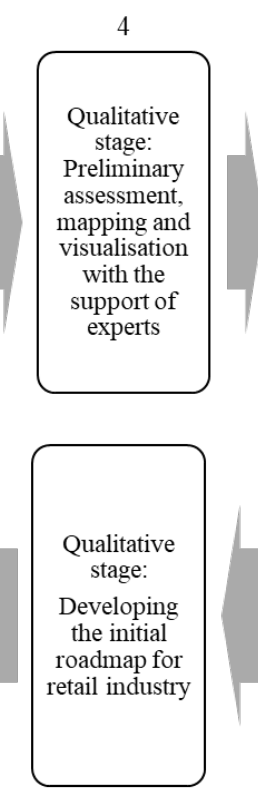
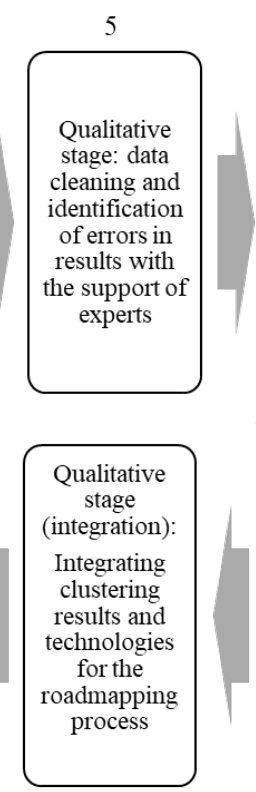

8

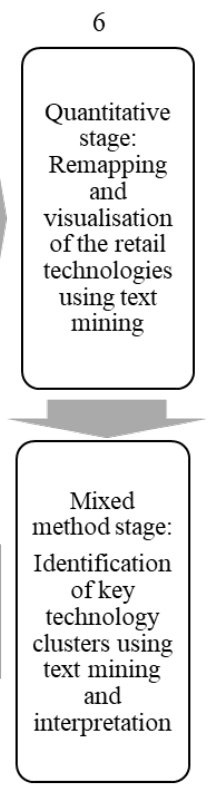

7

Figure 3 The integrated roadmapping process 


\subsection{Qualitative steps: Authors' and experts' involvement}

To increase the reliability and validity of the technology roadmapping process, a panel of retail experts was involved in follow-up interviews and continuous improvement. To collect accurate patent data at the initial stage, the authors developed a keyword list using previous research and retail technologies reports. This list was verified and expanded with the support of retail experts. A total of 12 retail experts, including technology managers, marketing directors, and retail managers, were involved. Experts were selected based on: (i) their degree of knowledge and input concerning the use of technology within different retail operational, including products, services, and processes; (ii) experience of engaging with projects that were focused on improving front or backend efficiency and effectiveness, and (iii) their specialised knowledge regarding key features and patterns of the chosen technologies, alongside their impact on activities, strategies, and issues related to the future of the retail sector. The retail experts worked across a range of company sizes and sectors.

Once the data was collected, the initial text mining pre-processing and calculations were performed and presented to the experts to verify and clean the data considering irrelevant terms. After collecting expert opinions on the initial results, the data was recalculated to finalise the retail patents' technological mapping and clustering. The authors labelled the final technological clusters using the keywords in the database, and the labels of the clusters were checked with the panel. Considering the identified applications and technologies, the clustering results are linked with the roadmapping model as a knowledge base for technology and products/services layers. For the roadmapping steps, we benefited from several studies [15], [42], [67], [70]. As such, the initial roadmapping model was completed considering different layers and based on the clustering results. At the same time, the timeline was adjusted according to the application date of patent documents (time-lag for pendency is 2 to 5 years, $0-12$ years for the first successful commercialisation and 5 to 10 years for its impact on the market [71- 
74]. To link clustering results to the roadmapping method, it was necessary to include a preliminary assessment of the clustering results and the applications. Accordingly, we first identified the key underlying technologies for each cluster and created a pool of technologies. To construct a roadmap we initially positioned technologies in one layer and linked them to applications. To establish the time positioning, we examined the set of technologies and their patent application date. We positioned them according to the timeline of the technologies, and subsequently adjusted this based on the comments of the experts. With respect to market/business drivers, these were initially developed on the basis of the patent documentation through reading the description section to identify the intended retail application. Supported by the experts, we then further assessed the key drivers that would influence the application. Adopting these steps follows a data-driven roadmapping approach [75], which is a semiautomated approach where a roadmap is adjusted manually. Sharing the initial roadmapping model with the experts enabled us to adjust the product/services linkages and timeline-based positioning. Once the roadmapping model was finalised, a simplified model was generated by merging similar items and adjusting links by retaining stronger links. Finally, a proof of concept for the retail industry was designed to illustrate the sector's likely future by interpreting the technological roadmap. After developing the roadmapping model focusing on the likely scenario and future, we also developed alternative scenarios and futures focusing on the wildcards [76-79]. For the wildcard development, we followed the approach of four different studies [76-79], while involving six of the experts (KI2, KI3, KI5, KI9, KI10 and KI12).

\subsection{Quantitative steps: Text mining approach}

The quantitative steps were completed using a text mining-based patent retrieval process, following the steps of other scholars [40], [80-82]. An increasing number of studies in science, technology, and innovation (STI) have adopted text-mining methods [83-86]. A few seminal 
studies are evident where similar methods are used for retail-oriented analysis [22], [87-93]. Our study consists of five critical stages: patent database selection, patent search, patent data optimisation, patent data analysis and visualisation, and the interpretation of results.

The biggest challenge in retail sector specific analysis is the lack of a reliable list of patent codes and technological terms to retrieve the required dataset. As explained previously in section 3.1, expert support and qualitative steps were utilised to increase the data reliability. The research and innovation areas in the retail sector were grouped based on the literature and then the qualitative examination of the sample retail patent data with the experts' support. The following list of retail technologies are shown to illustrate the list of technologies in this field:

- Administration and management of the retailing environment [15], [20], [27]

- Advertising, product management and in-store merchandising [1], [2], [13], [36]

- Data processing technologies and applications [1], [27], [34], [35]

- Payment and point of sale technologies [2], [13], [27]

- Retailing materials and specific items [1], [13], [26], [27]

- Security systems in retail [4], [13], [14]

- Storage, warehousing and inventory [13], [27], [37]

- Telecommunication technologies and IoT [4], [39], [48]

Based on the list above, the following search query is used to collect and create the required patent dataset. There were two search queries; "initial" (term based - lexical) and "final" (term based with patent codes) search queries. The final search query was created through iterative steps, which was based on the lexical search term strategy in reflection of the literature and expert opinion. In the final stage, only relevant terms were used (i.e. retail*) and relevant patent codes (i.e. A45C3/04) were identified based on the preliminary analysis by examining patent code frequencies for all the documents. We identified that the patent codes listed below were the frequently used and/or specific patent codes for the retail field (please see Appendix B for the detailed explanation to the patent codes). Please see the initial and final search querries 
below. The terms are combined with the patent codes, and the results are listed from the most relevant to the least. The least relevant patent documents are examined to see if any patent documents are not relevant to the retail-oriented technologies so we can exclude them. We identified some patent documents (less than 5\%) that were not relevant to the retail-oriented domain, despite the lexical term and patent code strategy. These patent documents are removed from the database based on the qualitative assessment step with the involvement of the authors and experts.

Initial search query: ((Retail* OR supermarket* OR shop* OR mall OR wholesale* OR store OR kiosk) AND (checkout OR payment OR "Loyalty point redemption" OR "point-of-sale" OR "point of sale" OR PayBooth OR "Product scanning" OR "Self-checkout" OR "Vending system" OR "Vending machine” OR "Retail Terminal”))

Final search query: ((Retail* OR supermarket* OR shop* OR mall OR wholesale* OR store OR kiosk) AND (A45C3/04 OR A47F 3 OR A47F 5 OR A47F 9 OR A47F10/02 OR B25J OR B32B 2439/70 OR B62B3/00 OR B65D OR B65G 1 OR B65G1/1375 OR G05D 1 OR G06F 17 OR G06F 19 OR G06K OR G06Q 10 OR G06Q 20 OR G06Q 30 OR G07D OR G07F OR G07G OR G08B13 OR G09F OR H04L OR H04M17 OR H04W OR Y10S 280/03 OR Y10S 280/04))

A result of nearly 27,000 granted patent documents were retrieved from USPTO, EPO, and JPO. The dataset was refined from duplicates by using patent IDs and titles of patent documents. Nearly 6,000 internationally repeating patents were eliminated before the remaining 21,070 patents were used for examination. The terms were pre-processed by first tokenising, merging synonym terms, and final cleaning with the stopwords list that was created for the retail industry. The terms were chosen with a minimum of ten-term frequency and with a TF-IDF threshold which led to 313 terms. Following these thresholds, Principal Component Decomposition (PCD) is used to explain $80 \%$ of variance, which covers $32 \%$ overall data (this 
result is significant considering the size of the data and high dimensionality of such text-based datasets). The PCD calculation led to 42 technological terms. These were then analysed using various calculation methods such as the co-occurrence matrix in VantagePoint software. The results of the matrix calculations were used to calculate the centrality measurements [94], [95]. The centrality measurements position the terms based on relevance to each other and also their overall relations to other terms. The positioning of terms based on the centrality calculations leads to the cluster of terms. Using the combination of terms represented in the visual, we link them to the patent documents in the database. After reviewing the patent documents in light of these terms, we can identify the clusters and label them accordingly. Each clusters are interpreted by going through the patent documents that belong to the illustrated cluster. Final clustering results were integrated with the roadmapping model. The results benefited from follow-up interviews with the panel of experts for final improvement.

\section{Results and discussion}

Our analysis uncovered eight key clusters of technologies where retail-oriented patenting is concentrated, as shown in Fig. 4. Table 4 shows the descriptions of the clusters identified in

Fig. 4. Accordingly, the visual can be interpreted as the key technologies and the relationship of the technologies specific to each cluster, as well as the intersecting clusters of interrelated technologies between clusters. Each cluster appears to have uniqueness concerning the use of technologies. However, there are intersecting technologies between different clusters, which would be expected for this sector, where many technologies are developed elsewhere and implemented for retail-oriented operations. For example, we see an overlap between clusters 7 and 8 due to the use of common technologies such as mobile technologies and systems and their use in both inventory and sales systems.

Our analysis reveals a generic distinction between these clusters. These distinctions are related to (i) their extent of innovativeness (whether the technology is a mainstream incremental 
innovation or a radical or breakthrough innovation) and (ii) the source of innovation (whether the technology is being adopted or developed specifically for the retail industry). For example, the technologies in cluster 2 (main shopping tools and items) are mostly incremental in nature and are specific to the retail industry. By contrast, cluster 6 (unmanned and automated systems) is more radical in nature with the technologies being adopted for retail operations. Having discussed the intersections of these clusters and their overall differences, the following sections examine each of the eight clusters in-depth to illustrate retail technologies.

\section{Table 4}

$\underline{\text { Cluster areas and their labels for retail technologies }}$

\begin{tabular}{lll}
\hline Cluster numbers & Labels & Examples for Relevant Technologies \\
\hline 1 & Intelligent marketing systems & Biometric databases marketing \\
2 & Main shopping tools and items & Shopping trolley and basket \\
3 & Self-service and intelligence systems & Storage based self-service systems \\
4 & Purchase and checkout technologies & Use of RFID in checkout \\
5 & Computer and data integrated technologies & Use of gift and value card data \\
6 & Unmanned and automated systems & Unmanned systems using robotics \\
7 & Sale systems and technologies & Mobile sale systems \\
8 & Inventory and ordering systems & Mobile inventory and ordering systems \\
\hline
\end{tabular}

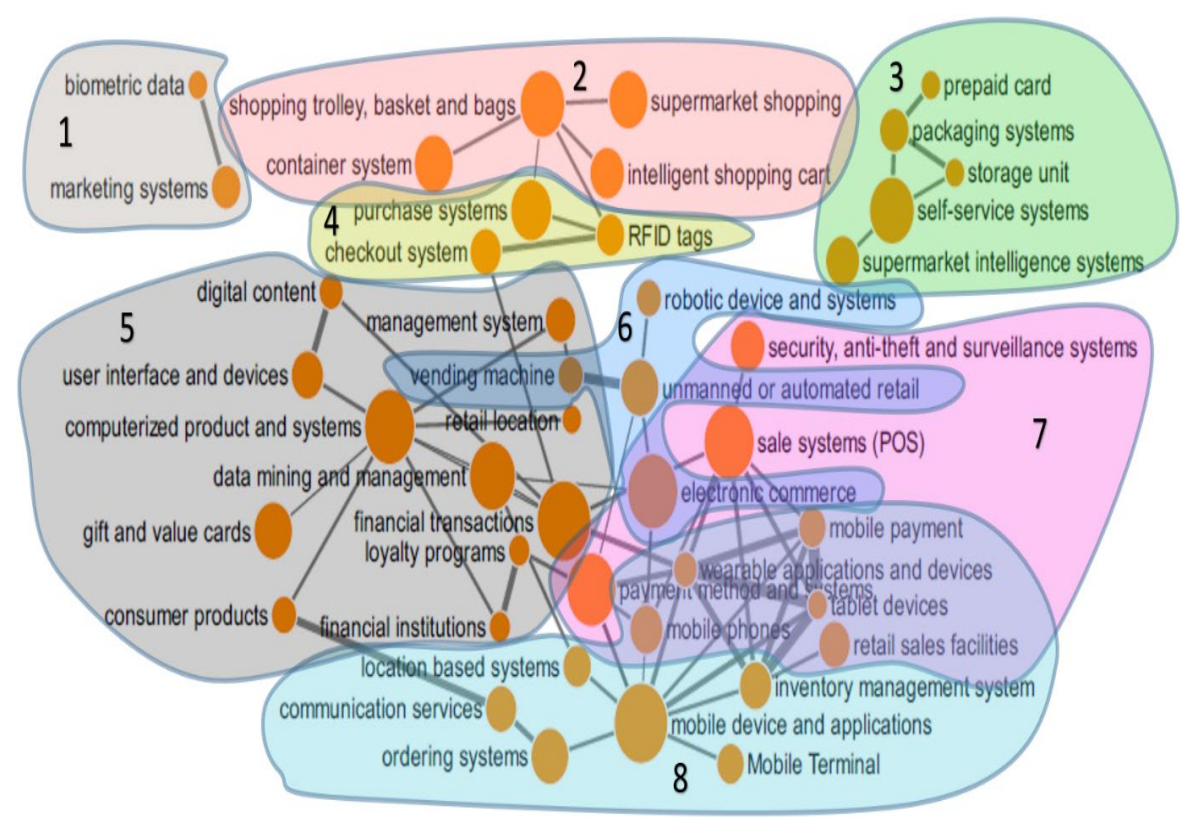

Figure 4 Clusters of technologies and identification of concentration zones in the retail sector The retail patents were also examined based on the distribution of the number of retail technologies by patent grant year, as shown in Fig. 5. Focus year is calculated based on the 
following formula (1) where this calculates the year in which the technology had the highest number of patents. Normalised year is calculated based on the average value between focus year and the earliest year (the first patent that is granted in a particular technology). The results identify a large difference between the focus year and the earliest year, which is expected due to initial patenting being followed by an umbrella or relevant patents. Based on this analysis, problems are evident in utilising the year of patenting as a sole measure for a technological forecast, to establish their market application and acceptance. However, these are useful indications when used alongside expert involvement to position the technology across the roadmap. Table 5 describes eight clusters that were analysed in this research.

$$
\text { Year }_{\text {focus }}=\frac{\sum_{n=2000}^{\text {Total Years }} n \cdot \text { Number of Patents }}{\text { Total Years }}
$$

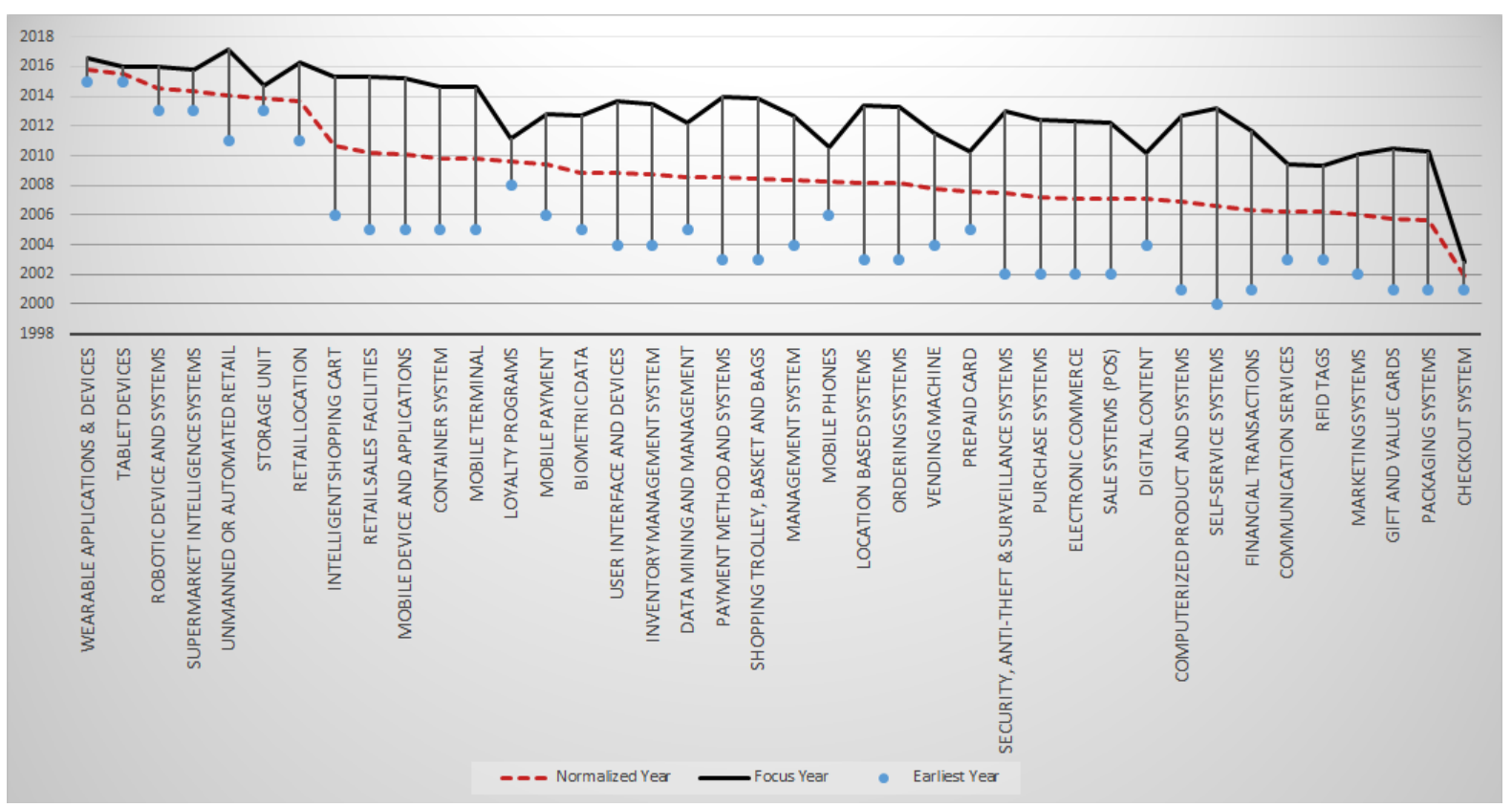

Figure 5 Distribution of Number of Retail Technologies by Patent Grant Year 
Table 5: Technology clusters

\begin{tabular}{|c|c|}
\hline 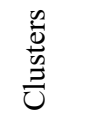 & Description \\
\hline 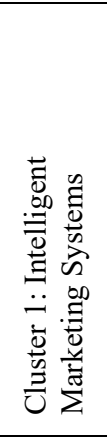 & $\begin{array}{l}\text { Several patents fall under the category of intelligent marketing systems. The rise in e-commerce and consumer preferences } \\
\text { continues to change positively towards online shopping, and data shows a rise in patents regarding customer data acquisition } \\
\text { and exploitation. Both cards and worn bracelets can be used in-stores for dealing with customer identification and location } \\
\text { information and act as a method for making purchases (US8453926B2). Stores can utilise RFID tags, which can relay data } \\
\text { for analysing customer interest and buying patterns regarding products based on their shelf location (BE1013810A3). } \\
\text { New and higher-level of innovative technologies are appearing in the retail marketing that can create automatic and } \\
\text { personalised messages for the customers based on (i) the current offers and events (US8639563B2), (ii) general biometric } \\
\text { data of the customers collected in stores (US9031857B2), (iii) biometric data to describe how customers psychologically } \\
\text { respond to products and information (US9361623B2), (iv) automatic behavioural information (US8812355B2), and } \\
\text { identification data (US9846883B2). Furthermore, there is an emergence in patents on television advertisement enabling } \\
\text { personalised images on the consumer's screen, instead of having one general and promotional message, through signal } \\
\text { processing locations (US7962931B2). }\end{array}$ \\
\hline 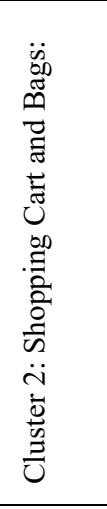 & $\begin{array}{l}\text { The cluster of the shopping cart and bag related technologies primarily relates to front-end innovations within bricks and } \\
\text { mortar stores to deliver a growing extent of automation in services alongside improvements in the customer experience. } \\
\text { Several patents also aim to provide efficiency improvements through specialised and automated cart collection vehicles } \\
\text { (US10071893B2; US6880652B2) and improved cart theft-avoidance security systems (CN205541039U; US8433507B2). } \\
\text { Developments aim to deliver self-powered motorized carts (US20080041644A1; US5064012A; US5899285A), which } \\
\text { include additional features, such as (i) carts designed for the disabled (US20130333961A1), (ii) built-in seating } \\
\text { (US4771840A), (iii) advanced software for collision avoidance (CN105785996A; US6008546A), and (iv) navigation } \\
\text { assistance (CN205615553U). Alongside motorised carts, innovations will integrate new technologies, such as Wi-Fi Zigbee } \\
\text { and particularly RFID, to monitor products entering the cart and enable automatic checkout when leaving the store } \\
\text { (CN102592229A; CN202748832U; US20140164176A1). Future innovations will also deliver intelligent carts integrating } \\
\text { (i) touch screens and payment technologies (CN104637198A; US20150206121A1), (ii) built-in speaker systems to } \\
\text { communicate scanned items (EP0923768B1), and (iii) weighing or camera-based recording technologies to ensure accuracy } \\
\text { and avoid theft (CN104376655B; CN104787102B; CN207993168U). These technologies aim to decrease shopping time } \\
\text { and provide visual information on purchased items and promotional messages (CN202896621U; EP0923768B1). }\end{array}$ \\
\hline 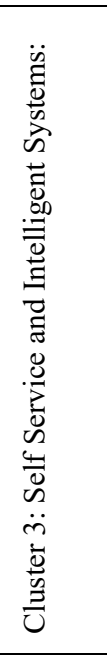 & $\begin{array}{l}\text { This cluster includes a range of intelligent technologies to automate the shopping journey and deliver improvements in } \\
\text { checkout and item handling. Innovations to existing handheld devices will enable the scanning of shopping while } \\
\text { communicating with a centralised server to enable an automated checkout experience (EP1031936B1; US6112857A). New } \\
\text { technologies will enable both handheld devices or consumers' phones to provide additional product information and } \\
\text { shopping lists (US10204369B2; US6604681B1; US8412590B2), and coupon systems (US6616049B1). While positioning } \\
\text { can be used to deliver targeted messages (US7783527B2), it can help consumers navigate stores and find desired items } \\
\text { (CN104408633A; KR101795594B1; US6317718B1; US7873547B2). Within the field of self-checkout, innovations will } \\
\text { improve existing POS systems while decreasing human intervention through (i) voice or visual guidance (EP1115100A2), } \\
\text { (ii) voice input for non-scannable items (US8732024B2), and (iii) fingerprint and recognition for payment and age } \\
\text { authentication (CN206470885U; KR101402497B1). Image recognition will be used to identify items as they pass through } \\
\text { a tunnel-like or camera-based systems (US7954719B2; US8430311B2; US9600982B2), while dynamically learning items } \\
\text { (US8494909B2). Image capture will increasingly compete with traditional self-checkout to record goods' movement into } \\
\text { identifiable shopping containers and track purchasing (US7168618B2). Automated RFID gate systems will also provide the } \\
\text { potential of all items being automatically registered as consumers exit the store (US9864971B2). In-store product } \\
\text { information will also be provided with visual displays featuring avatars (US8199966B2). } \\
\text { Within online retailing, innovations will deliver increasingly targeted recommendations and sales promotions } \\
\text { (KR20010076971A), helping consumers avoid selecting the wrong items (KR20010076971A; US20150088642A1), and } \\
\text { assisting in product selection based on carbon footprinting (US8738432B2). }\end{array}$ \\
\hline 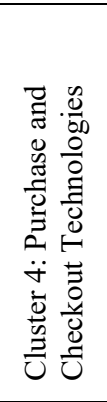 & $\begin{array}{l}\text { Technologies in this cluster show incremental levels of innovation. Optical sensors are already being incorporated in the } \\
\text { self-checkout systems, which will increasingly be used to work alongside the weighing trays and payment systems to provide } \\
\text { a more robust security feature (US6343739B1, US6990463B2). Furthermore, these optical sensors will provide robotic } \\
\text { assistance in moving goods across the store (US6409081B1), and customers could get any products at the point of sale } \\
\text { locations (US7422148B2). A variation of this technology is also planned to be used in restaurants for quick service. Based } \\
\text { on the optical sensors, automatic planogram can be made for enhanced customer experience (US7493336B2). } \\
\text { In the future, customers will be able to complete a purchase at self-checkout pillars throughout the store (US6990463B2). } \\
\text { There will be negotiating systems capable of gathering all the product costs to provide personalised offers (US8515824B2). } \\
\text { In online shopping, customers will add a product in a basket directly from a promotional video without interrupting or } \\
\text { stopping the video (US9087358B1). Systems will also allow the stores to automatically place several orders from } \\
\text { predetermined distinguished suppliers (US9117214B2). }\end{array}$ \\
\hline
\end{tabular}




\begin{tabular}{|c|c|}
\hline 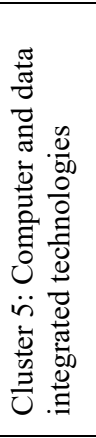 & $\begin{array}{l}\text { The cluster of technologies in this area highlights the application of computer science-related approaches to retailing } \\
\text { operations. Some of these approaches are implemented for data processing for further analysis, while many cloud-based } \\
\text { retail management approaches are apparent (US9747632B2). One of the most common areas using data mining and machine } \\
\text { learning is the use of gifts and value cards and examination of the customers' data (JP6293131B2). There are patents found } \\
\text { related to better use of gift card considering its physical and mobile or virtual environment availability (US9741072B2). A } \\
\text { recent development in this area includes social network-based gift-giving (US20140351015A1) and collaborative shopping } \\
\text { (US10002337B2). } \\
\text { The highest level of innovations in this area is mainly related to big data or more advanced machine learning applications. } \\
\text { For example, advanced machine learning applications are applied in various conditions such as sales predictions, } \\
\text { recommendation systems, smart pricing, and payment or transaction analysis (US10121116B2; US20140122229A1; } \\
\text { US20140330670A1; US20190026762A1). This area's future shows that decision-making will be increasingly supported or } \\
\text { completed by the implementation of machine learning techniques. }\end{array}$ \\
\hline 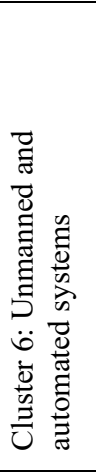 & $\begin{array}{l}\text { Technologies in this cluster are found to be either those supporting the existing retail operations where there is a certain } \\
\text { degree of human involvement, or those planned to replace human involvement at different stages of the retail process. Lower } \\
\text { level technology innovation consist of many solutions related to the vending machines, like integration of 3D multi-sensor } \\
\text { touch (US8463430B2), mobile device assisted machines (US6584309B1), and 3D printer based vending machines } \\
\text { (US9418503B2). The higher levels of innovation in this cluster aim to replace human involvement in phases of the retailing } \\
\text { process, including robot-enabled warehouse operations (US9592961B2), techniques for automating transactions } \\
\text { (US9846863B2), and automated monitoring systems (US6659344B2). The most considerable number of innovations in this } \\
\text { cluster are related to the unmanned front-end and backend retail operations. Many integrated patents are found to perform } \\
\text { customer interaction from the point of entry to the final checkout at the front end. There are several advancements at the } \\
\text { back end of retail operations using robotics (US9592961B2) and AGVs (US9864371B2) for inventory and order } \\
\text { management. In more advanced cases, the order fulfilment operations are completed by UAVs (US10112712B1). However, } \\
\text { the integration between front and back-activities remains an issue as many patents are designed for unmanned operations at } \\
\text { particular stages only. }\end{array}$ \\
\hline 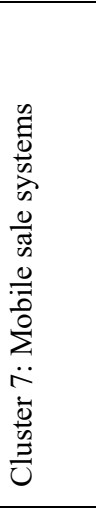 & $\begin{array}{l}\text { Technologies in this cluster primarily support multichannel retailers (US20030004822A1; US20040138986A1; } \\
\text { US20170024804A1). The diversity of mobile systems' application creates challenges and opportunities for retailers to focus } \\
\text { on their mobile sales and service systems (KR100456986B1; US9015207B2). In this sense, some patents include mobile } \\
\text { methods using an alias (US20110040686A1; US7848980B2), payment systems that conduct transactions without the need } \\
\text { to sign up (US8249965B2), and systems for improved randomised mobile payments (US9117210B2). Moreover, the } \\
\text { diversity of transactions for mobile sales remains critical to retailers. In addition to desktop and mobile websites, there is } \\
\text { now the ability to directly purchase from the social media platform using a voice assistant device. Here patents include: (i) } \\
\text { computer program codes for using mobile devices (AU2011237387B2; US8285210B2), (ii) routing methods that enable } \\
\text { obtaining information from multiple sources by the retailer (JP3742058B2; US6999943B1), and (iii) systems for } \\
\text { computerized bill consolidating (US5943656A; US5978780A; US6052671A). Furthermore, a growing interest in mobile } \\
\text { sales systems has been mobile payments through wearable application devices. These include wearable display devices with } \\
\text { the ability to integrate payment methods, including Apple Pay (US20120016793A1; USD719570S1; US9384481B2), and } \\
\text { body wearable information processing devices (KR100408009B1; US6619835B2). These technologies provide a greater } \\
\text { extent of information about customer behaviour and impact the retailer-customer experience via different channels. }\end{array}$ \\
\hline 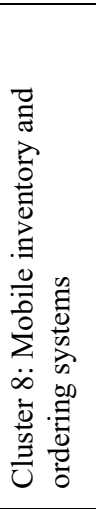 & $\begin{array}{l}\text { This cluster highlights the importance of inventory management systems within different cycles of receiving, storing and } \\
\text { shipping the product to reach its final user. Some of the patents include systems that monitor inventory amounts and provide } \\
\text { availability information (CN102498494B; US6341271B1; US7766242B2), systems related to the collection of information } \\
\text { using RFID tags (US8321302B2), and data communication systems for requisition and inventory management systems } \\
\text { (AU2008221531B2; US5712989A; US7588185B2). Moreover, advances in cloud solutions for inventory management and } \\
\text { ordering systems have enabled inventory processing complex activities. These include various store mobile cloud } \\
\text { application systems that execute a retail store purchasing system (US20130232083A1; US20170083968A9). They also have } \\
\text { barcode scanners' plurality and scan guns integrated with a mobile tablet device carried by employees (US9747632B2; } \\
\text { US8720771B2). While the cloud-based application can track warehouse activities, it can facilitate two-way host } \\
\text { communication between a host and local computer (US20100332629A1; US5712989A). Further, using wireless mobile } \\
\text { handheld devices connected to a central warehouse management system allows floor staff to scan shipments efficiently and } \\
\text { log them in their cloud-based system. Examples include a connected and computer-based ordering system (US8190483B2; } \\
\text { US8660906B2) and a method of ordering service performed via a user terminal connected to a central data processing device } \\
\text { (US6356874B1; US7725344B2). }\end{array}$ \\
\hline
\end{tabular}

\section{Technology Foresight}

\subsection{Technology Roadmapping and Wildcards}

To develop a roadmap based on our analysis results in Table 5, we undertook a preliminary

examination phase by categorising the key underlying technologies for each group of 
inventions based on eight identified clusters. Secondly, we categorised patent documents based on their front and backend uses in the retailing process to make our roadmapping data more specific to the retail environment. Thirdly, benefiting from the clustering results and application areas of these patents, we linked patent documents to market or business-related needs. Subsequently, we examined the retail technologies adding three-time dimensions, namely: (i) near, (ii) mid, and (iii) far future. Applications in each category were incorporated considering the time dimensions. The preliminary roadmapping result is improved with the support of experts focusing on time dimensions and the linkage of technologies with applications and market/business drivers.

The applications based on the clustering results and the roadmapping method are presented in Fig. 6. Concerning the time dimension, we considered their acceptance and adoption by retailers. When only a few retailers adopted these applications or accepted them as a pilot program, we accepted them as not current. As the retail operations can differ for online, instore, and omnichannel, Fig. 6 introduces different shapes of boxes for both front and backend applications (see legend box). Also, different boxes were created for business or market needs for the market/business driver section.

Looking at the final category, in which the business drivers and market needs are presented by linking them to their relevant technologies, the results of the roadmapping reveal that the majority of applications are developed considering the business drivers rather than market drivers. This may be due to the required efficiency in high volume and low margin profits in retailing. Retailers will seek to simplify the checkout process with intelligent carts, trolleys, and payment technologies, while also aiming to minimise labour-intensive tasks with unmanned and intelligent operations.

A broader look at the retail roadmapping focusing on the timeline of technologies, applications (based on patents), and changing business/market needs; it is evident that the retailing 
environment and its operations, will be more intelligent at different levels. To begin with, the retailing environment will be semi-automated, where unmanned solutions manage some operations and processes. Finally, retailing will ultimately reach its most efficient stage with fully unmanned back- and front-end operations.

The major issue for the fully automated retail operations appears to be achieving full integration between the back and front end. It seems that many of these solutions are developed by different firms where they focus on their expertise (i.e., improving the efficiency of the backend operations primarily). However, we firmly believe a more integrated and holistic approach is required to interlink both ends at full capacity for a fully unmanned supermarket.

The technology roadmapping for the retailing industry presented identifies the likely retailing technologies scenario, based on our projection using the patent data and expert opinion. However, this future may not happen if unexpected events happen or conditions arise. Wildcard analysis is a tool that assists with brainstorming for alternative futures and scenarios. Accordingly, following the studies of [76-79], we developed Table 6 by focusing on four categories of wildcard scenarios that would alter the projected roadmap that is presented in Fig. 6. We further illustrated how the wildcard analysis in Table 6 could alter the projected PoC in Fig. 7. Please see Table 6 for the detailed illustration of different scenarios and their impacts. 


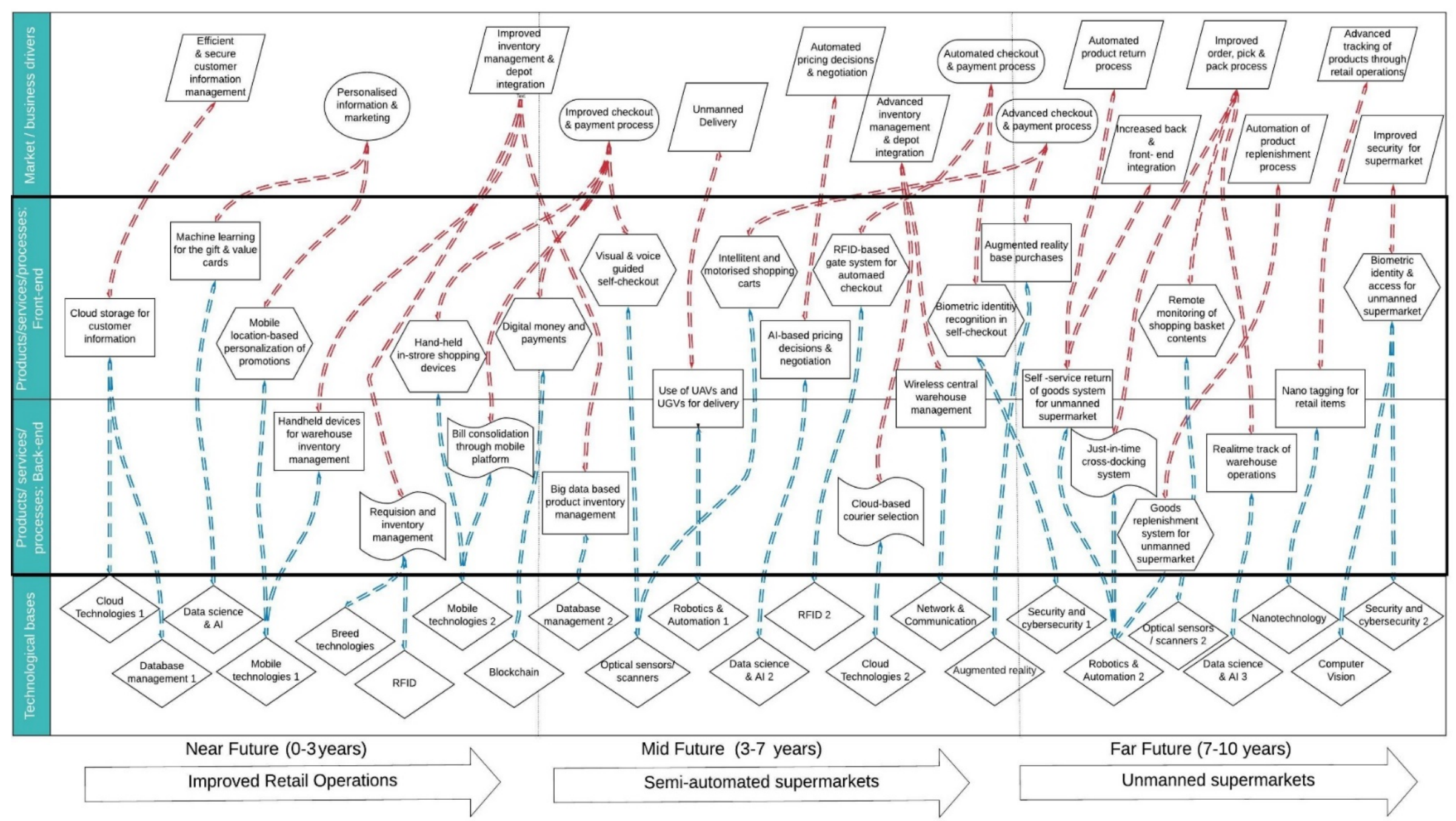

$\square$ Business Driver $\bigcirc$ Market needs $\square$ Market needs \& Business Drivers $\square$ Bricks \& MortarBusiness Driver $\square$ Market needs $\square$ Market needs \& Business Drivers $\diamond$ Technology Basis

Figure 6. Roadmap for the retail sector 
Table 6: Linking wild cards to future scenarios Selected Wildcard Scenarios

Science The impact of Blockchain

and (distributed Ledger

Technology Technologies) on the business architectural chain where it is fully distributed, and many different companies take place

Cyber Attacks disturbing the digital, unmanned and online retail operations

Rise of AI - Humanity reaches to the superintelligence and superintelligence disturbing or taking control of all digital world and robotic

Technological failures related to unmanned vehicles and robotics causing accidents and leading to national/international bans on their widespread use

Ecology Geomagnetic storm affecting electronic devices

\section{Summary of Impacts on Forecast}

Larger organisations may be replaced by many SMEs where the products are distributed without large retailers.

The current linear structure of retailing may be replaced by a distributed network, resulting in an increased importance of blockchain technology. SMEs may have a stronger involvement in the retailing process.

Social resistance can lead to slow or partial adoption of technologies. It can also slow down automation adoption and lead to vulnerability of retail activities. This can redirect the demand back to traditional formats of retailing, leading to complete reverse of our PoC model, i.e., moving back from unmanned to labour-controlled retail operations.

\section{Retail operations may be forced to go back to the} traditional retailing process if they cannot find a sustainable limit superintelligence access, thus leading to the online aspect solution to the new world's control of superintelligence.

Lack of, or delayed, implementation of techno
to robotics and unmanned vehicles by retailers.

Summary of Impact on POC

The PoC model will be impacted by a distributed busines

network structure, resulting in a direct supply chain mechanism

where suppliers and retailers earn consumer loyalty by building

trust in these distributed systems where products and services are delivered to consumers directly from their sources.

Blockchain based distributed platform technologies may replace those platforms and technologies that are designed for central actors such as current supply chain management technologies and systems.

Based on our PoC model, only the future in-store based model (upper side) can be more realistic to achieve as there is a higher level of human control. However, in extreme levels of

cyberattacks, this may not be achievable either. For instance, cyberattacks can hack in-store systems leading to chaos in the stores and this can push retailers to go back to the traditional approaches at different parts of retailing.

All retail organisations may prefer to use offline methods to of the PoC becoming redundant/failing to emerge. Alternatively, smart approaches may be implemented with the narrow AI applications without the internet access to the retailing operations.

Robotics and unmanned vehicles may not feature within the PoC with respect to the fulfillment of online delivery or backend operations.

Leads to disturbance in energy supply, damage in energy infrastructure, electricity shortage, satellite technology and unbalanced demand for energy.
Impacts the entire value chain of retail activities. Retail operations, either semi-automated or unmanned, are driven by different forms of electricity and satellite technology. A geomagnetic incident can completely disturb different technology-based innovations along the retail value chain. 
Significant acceleration of climate change and global warming

Political and legal system

Increasing extent of ultranationalisation evident across the globe (failure of global system, democracy, capitalism innovations within the forecast and decreased collaboration between supply chain members, while increasing

Rapid increase in environmental and sustainable socioeconomic development in particular industries including energy, manufacturing, logistics, and e-commerce.

bureaucracy. Some of the technologies are dominated by certain countries, such as robotics and in the case of ultranationalism, it may be difficult to source the required technologies by some of the countries.

Ban on consumer data collection and retention Privacy of customers and GDPR

Legal and infrastructure barriers for unmanned vehicles and robotics

Because of the increasing debate on privacy, Government can ban consumer data collection. This can result in those technologies linked to customer data collection and storage failing to diffuse into the market and thus becoming absent from the forecast.

Governments may ban the use of robotics and unmanned vehicles for the retail operations limiting the implementation of such technologies.

Society and Growing societal resistance culture
Automation and robotics growth change our understanding of what it is to be human virtualisation, augmentization of life, negative perception for superintelligence and automation replacing labor force. This will lead to social resistance against technological change.

Environmental concerns grow over the impact of retailer

business operations, alongside a backlash against packaged goods sales and plastic packaging
Growth in technologies linked to the environment and those that allow refill in stores and reduce plastics usage.

Delivery methods, such as unmanned vehicles, will be dominated by technologies that improve sustainability. A potential switch to local supply of goods may necessitate the introduction of new supply chain management technologies.
Environmental deteriorating conditions lead to changes in the production and consumption of products, services, and processes at a much faster pace than thought. This requires adoption and diffusion of technologies, concerning manufacturing, inventory management, and e-commerce in the $\mathrm{PoC}$, with an unexpected rate and beyond control

Prevents disruption and shifts to new technological premises in societal management. This can have an impact on both in-store and online elements of PoC. This problem would be apparent in technologic areas where only few nations dominate certain technologies.

Restrictions on data collection policies would impact our PoC model especially considering the usage of security, face recognition, fingerprint related technologies.

Robotics and unmanned vehicles may not feature within the PoC with respect to the fulfillment of online delivery or backend operations. Further development may be necessary to meet the legal requirements set by the government. If the companies cannot fulfill the requirements, the PoC may not unfold the way it is proposed.

Social resistance can lead to slow or partial adoption of technologies. It can also slow down automation adoption and lead to vulnerability of retail activities. This can alter the different parts of the PoC, such as implementation of robotics in the store or unmanned inventory management.

Refilling of packaging may lead to reduced ability to purchase online for home delivery, in-store refilling may dominate home delivery due to ease of refilling solutions, growth of direct-toconsumer subscription models from manufacturers. There is also concerns about delivery packaging which can complicate robotic delivery process, as indicated in the PoC. 


\subsection{PoC for Retail Technologies}

Fig. 7 presents a proof of concept (PoC), developed from our text mining and roadmapping findings. The PoC develops upon the roadmap by revealing how each of the technologies will link to different future retailer operations. To develop the PoC, we began with the clusters (Section 4) and examined how the technologies related to different retailer operations [96], [97]. This enabled us to link them to four types of the back of house and warehouse operations and five types of operations relating to the retail sector's front of the house. This was further reinforced through insights from the roadmap, and based on this, we developed the PoC to reflect how future technologies would impact each of these operational areas. Fig. 7 captures each of the activities horizontally: The centre captures the back-house, while front-house activities are presented across the top and bottom of the figure (in-store positioned towards the top and online towards the bottom). Thus, the $\mathrm{PoC}$ provides a foresight of the future of technologies applied across retailers' key operations.

Starting from the inbound processes, within the back of house activities, nanotechnology tagging forms a critical future method for scanning products, enabling retailers to track the product as it moves along different parts of the supply chain. The data generated will also be incorporated with AI-based inventory management systems. In the warehouse, unmanned equipment and goods replenishment systems will undertake pick and pack activities and prepare products for dispatch to consumers or bricks-and-mortar stores. Finally, cloud-based systems will assist in the management of consumer information and courier selection.

The retailing trajectory is moving towards fully automated unmanned stores, and warehouses with limited human input from the point products are received from suppliers until their delivery to consumers. Regarding online and bricks and mortar technology development, patents indicate the integration of biometric identity systems to grant access to both retail stores 
and websites. Furthermore, customers will increasingly receive personalised promotions based on their location. Within bricks and mortar stores, intelligent and motorised shopping carts will begin to replace traditional carts with the capability of automatically monitoring products placed into them. Meanwhile, RFID-based gate checkouts will emerge and integrate with these carts to track contents before payment and exiting the store. Online purchasing will move towards augmented and virtual reality purchase experiences. For both retail shopping streams, mobile bill consolidation and biometric payment systems will expand as payment methods. Finally, products can be delivered and returned by UAV \& UGV delivery systems.

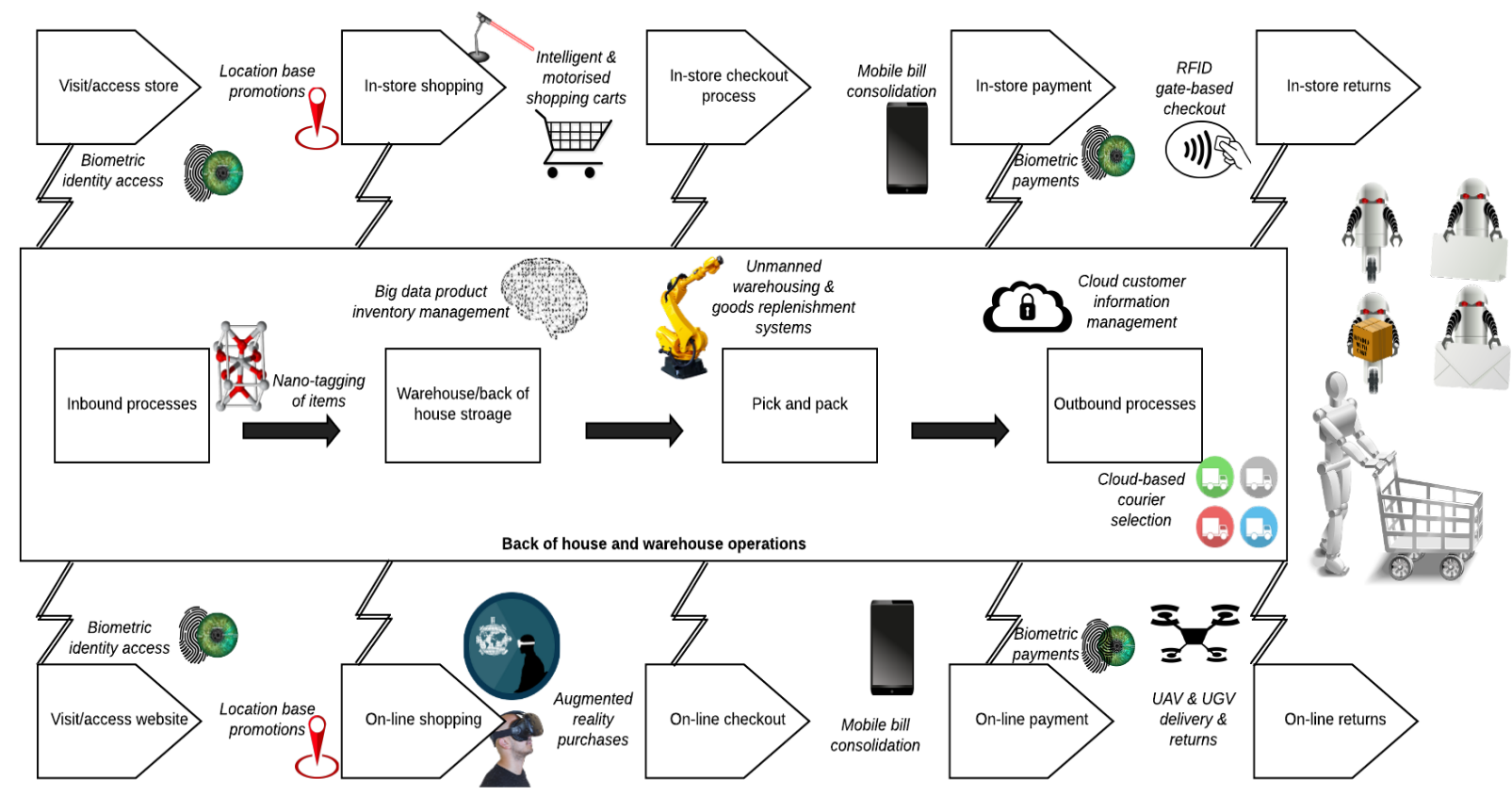

Figure 7. Proof of concept $(\mathrm{PoC})$ for the future of retailing

\section{Conclusions}

This paper has examined retail technologies by firstly clustering them, and secondly implementing them into the technology roadmapping model to foresight the future of retailing. As a result, a $\mathrm{PoC}$ is developed to illustrate potential retail operations using advanced technologies. We performed this by examining the patent documents considering technologies, their applications, and market-oriented levels. Specific to this study, we separated the front- 
and backend applications to show potential and missing links within the sector. Further, this study shows a clear direction for future applications with underlying technologies for key firms to prepare for the future of retailing.

This study has both practical and methodological contributions. Our approach showed that the roadmapping process could be enhanced by applying a sequential method where the textmining technique is integrated with qualitative methods involving a panel of experts. Our approach minimised the weaknesses of quantitative or qualitative approaches. Quantitative and especially text-mining methods have reliability and validity issues, where utilising machine learning approaches in data retrieval and data pre-processing methods have limitations in selecting or eliminating the required terms. Furthermore, the quantitative approaches required several iterations and optimisation for the final presentation of results. This was executed using the opinion of the panel of experts. However, their opinions have weaknesses due to the potential bias and subjectivity in the decision for the future directions of an industry or technologies. To minimise the error, a more extensive and more time-consuming qualitative approach is required (i.e., Delphi). By integrating both approaches in this research, the weaknesses of each approach were minimised. Compared to other approaches and steps, such as the suggested workshop steps by Phaal et al. [15], we identified that the patent-based text mining approach helps inform experts to provide insights into the vital retailing technologies and their potential future directions. Comparing our method to other approaches, such as bibliometrics or text mining as the only roadmapping source, there could be several errors in the results due to the lack of information in data processing or interpretation steps, where panel inputs are limited. As such, we can clearly see the benefits of our integrated approach. This is also mentioned by Li et al. [59], in their bibliometrics integrated roadmapping studies. However, any foresight study will contain some extent of error in predictions considering the dynamic nature of markets and technologies. 
This study has three practical contributions. First, it provides the clustering results for the retail industry, which classifies the technological categories and the activities in the field. As a result of the clustering, we identified eight retail-specific technological domains: (i) intelligent marketing systems, (ii) main shopping tools and items, (iii) self-service and intelligence systems, (iv) purchase and checkout technologies, (v) computer and data integrated technologies, (vi) unmanned and automated systems, (vii) sale systems and technologies, and (viii) Inventory and ordering systems. This analysis identified clusters of technologies that have not been captured by prior studies [14], [27], including unmanned and automated systems, mobile sale systems, and inventory and ordering systems.

Second, we offer a roadmapping model by integrating the clustering results and showing the potential future of retail in different phases and layers. Using the roadmapping model, we successfully illustrated the shift from incremental improvements to fully unmanned retail operations. As part of this model, we showed critical technologies that are expected to be the key competitive sources for the future of retailing. We then linked these technologies to products, services, and processes separating them as back and front-end operations to ensure the retailing context's applicability. Finally, market and business requirements are linked, revealing why the underlying technologies will be required and how the potential retailing services will fulfil those needs.

Third, we develop a PoC model by illustrating retail technologies and operations in an integrative fashion. We use this model to foresight the future of retailing with relevant examples that are derived from the roadmapping model. This was an appropriate way of showing differences in how online and in-store shopping will likely take place in the future. The PoC model also indicates how the retailing is moving towards fully automated systems, limiting the requirements of the human inputs. 
Our research is not without its limitations, and while we fulfilled all the intended objectives, our results could be extended, considering the retail industry-specific aspects. Firstly, future roadmapping studies should provide more detailed results on specific retailing technologies (i.e. retail-specific blockchain technologies), and their diffusion across different sub categories. This would complement the present study's comprehensive approach. Secondly, case study research would further our analysis, and applying this method to a specific retailing company. Third, we suggest that our method should be applied across further industry sectors. Our study was conducted within a sector largely dependent on technologies that external technology providers develop; we suggest this approach should be further developed by applying it in other similar sectors, such as low technology industries. Fourthly, the roadmapping model of this study is based on patent documents. Hence we could not cover all technologies if an organisation did not patent their retail-related technologies. Accordingly, another study could follow a similar method using academic publications. Finally, while we integrated roadmapping with text mining and expert opinion to increase the accuracy of results, future studies can extend this by benefiting from a questionnaire or a Delphi method to extend our results.

\section{Acknowledgement}

The authors would like to thank the retail experts for their contributions to this study. The contributions in this article by Dr. Sercan Ozcan was prepared within the framework of the Basic Research Program of the National Research University Higher School of Economics.

\section{References}

[1] D. Grewal, A. L. Roggeveen, and J. Nordfält, "The Future of Retailing," J. Retail., vol. 93, no. 1, pp. 1-6, Mar. 2017.

[2] E. Brynjolfsson, Y. J. Hu, and M. S. Rahman, "Competing in the Age of Omnichannel Retailing," MIT Sloan Manag. Rev., vol. 54, no. 4, pp. 23-29, 2013.

[3] R. G. Richey, M. Tokman, and L. R. Skinner, "Exploring collaborative technology utilization in retailer-supplier performance," J. Bus. Res., vol. 61, no. 8, pp. 842-849, Aug. 2008.

[4] W. Reinartz, "In the Future of Retail, We're Never Not Shopping," Harv. Bus. Rev., p. 3, 2016.

[5] S. K. Roy, M. S. Balaji, S. Sadeque, B. Nguyen, and T. C. Melewar, "Constituents and consequences of smart customer experience in retailing," Technol. Forecast. Soc. Change, vol. 124, pp. 257-270, 2017. 
[6] Raconteur, "Future of Retail - E-commerce," The Sunday Times, 2017.

[7] Venkatesh, J. A. Aloysius, H. Hoehle, and S. Burton, "Design and Evaluation of Auto-Id Enabled Shopping Assistance Artifacts in Customers' Mobile Phones: Two Retail Store Laboratory Experiments," MIS Q., vol. 41, no. 1, pp. 83-113, 2017.

[8] Raconteur, "Future of Retail," The Sunday Times, 2018.

[9] M. Miozzo and L. Soete, "Internationalization of services: A technological perspective," Technol. Forecast. Soc. Change, vol. 67, no. 2-3, pp. 159-186, Jun. 2001.

[10] Lee, "Strategies for technology-driven service encounters for patient experience satisfaction in hospitals," Technol. Forecast. Soc. Change, vol. 137, pp. 118-127, 2018.

[11] J. E. Collier and D. L. Sherrell, "Examining the influence of control and convenience in a selfservice setting," J. Acad. Mark. Sci., vol. 38, no. 4, pp. 490-509, 2010.

[12] V. Kumar, A. Anand, and H. Song, "Future of Retailer Profitability: An Organizing Framework," J. Retail., vol. 93, no. 1, pp. 96-119, 2017.

[13] V. Shankar, "How Artificial Intelligence (AI) is Reshaping Retailing," J. Retail., vol. 94, no. 4, pp. vi-xi, 2018.

[14] F. von Briel, "The future of omnichannel retail: A four-stage Delphi study," Technol. Forecast. Soc. Change, vol. 132, pp. 217-229, 2018.

[15] R. Phaal, C. Farrukh, and D. Probert, "Customizing roadmapping," Res. Technol. Manag., vol. 47, no. 2, pp. 26-37, 2004.

[16] M. Han and Y. Geum, "Roadmapping for Data: Concept and Typology of Data-Integrated SmartService Roadmaps," IEEE Trans. Eng. Manag., 2020.

[17] Y. Okada, Y. Kishita, Y. Nomaguchi, T. Yano, and K. Ohtomi, "Backcasting-Based Method for Designing Roadmaps to Achieve a Sustainable Future," IEEE Trans. Eng. Manag., pp. 1-12, 2020.

[18] M. Gershman, S. Bredikhin, and K. Vishnevskiy, "The role of corporate foresight and technology roadmapping in companies' innovation development: The case of Russian state-owned enterprises," Technol. Forecast. Soc. Change, vol. 110, pp. 187-195, 2016.

[19] O. H. Bray and M. L. Garcia, "Technology roadmapping: The integration of strategic and technology planning for competitiveness," in Innovation in Technology Management - The Key to Global Leadership, PICMET 1997: Portland International Conference on Management and Technology, 1997.

[20] X. Yu and B. Zhang, "Obtaining advantages from technology revolution: A patent roadmap for competition analysis and strategy planning," Technol. Forecast. Soc. Change, vol. 145, pp. 273283, 2019.

[21] D. P. de Alcantara and M. L. Martens, "Technology Roadmapping (TRM): a systematic review of the literature focusing on models," Technol. Forecast. Soc. Change, vol. 138, pp. 127-138, 2019.

[22] Y. Jeong and B. Yoon, "Development of patent roadmap based on technology roadmap by analyzing patterns of patent development," Technovation, vol. 39-40, no. 1, pp. 37-52, 2015.

[23] B. Yoon, R. Phaal, and D. Probert, "Morphology analysis for technology roadmapping: application of text mining," $R \& d$ Manag., vol. 38, no. 1, pp. 51-68, 2008.

[24] S. Lee, S. Kang, Y. S. Park, and Y. Park, "Technology roadmapping for R\&D planning: The case of the Korean parts and materials industry," Technovation, vol. 27, no. 8, pp. 433-445, Aug. 2007.

[25] R. Phaal, C. J. P. Farrukh, and D. R. Probert, "Technology roadmapping: A planning framework for evolution and revolution," Technol. Forecast. Soc. Change, vol. 71, no. 1-2, pp. 5-26, Jan. 2004.

[26] J. Short, "The art of writing a review article," Journal of Management, vol. 35, no. 6. pp. 13121317, 2009.

[27] K. Willems, A. Smolders, M. Brengman, K. Luyten, and J. Schöning, "The path-to-purchase is paved with digital opportunities: An inventory of shopper-oriented retail technologies," Technol. Forecast. Soc. Change, vol. 124, pp. 228-242, 2017.

[28] B. Weijters, D. Rangarajan, T. Falk, and N. Schillewaert, "Determinants and Outcomes of Customers' Use of Self-Service Technology in a Retail Setting," J. Serv. Res., vol. 10, no. 1, pp. 
3-21, Aug. 2007.

[29] S. G. Dacko, "Enabling smart retail settings via mobile augmented reality shopping apps," Technol. Forecast. Soc. Change, vol. 124, pp. 243-256, 2017.

[30] J. Heller, M. Chylinski, K. de Ruyter, D. Mahr, and D. I. Keeling, "Let Me Imagine That for You: Transforming the Retail Frontline Through Augmenting Customer Mental Imagery Ability," J. Retail., vol. 95, no. 2, pp. 94-114, 2019.

[31] E. Pantano, C. V. Priporas, and C. Dennis, "Managing consumers' dynamics within the emerging smart retail settings: Introduction to the special issue," Technological Forecasting and Social Change, vol. 124, pp. 225-227, 2017.

[32] J. J. Inman and H. Nikolova, "Shopper-Facing Retail Technology: A Retailer Adoption Decision Framework Incorporating Shopper Attitudes and Privacy Concerns," J. Retail., vol. 93, no. 1, pp. 7-28, 2017.

[33] F. Gallouj, K. M. Weber, M. Stare, and L. Rubalcaba, "The futures of the service economy in Europe: A foresight analysis," Technol. Forecast. Soc. Change, vol. 94, pp. 80-96, May 2015.

[34] D. Antons and C. F. Breidbach, "Big Data, Big Insights? Advancing Service Innovation and Design With Machine Learning," J. Serv. Res., vol. 21, no. 1, pp. 17-39, 2018.

[35] I. Bildosola, R. M. Río-Bélver, G. Garechana, and E. Cilleruelo, "TeknoRoadmap, an approach for depicting emerging technologies," Technol. Forecast. Soc. Change, vol. 117, pp. 25-37, 2017.

[36] D. Grewal, R. Krishnan, M. Levy, and J. Munger, "Retail Success and Key Drivers," in Retailing in the 21st Century: Current and Future Trends, vol. 24, no. 3, M. Krafft and M. K. Mantrala, Eds. Berlin, Heidelberg: Springer Berlin Heidelberg, 2010, pp. 15-30.

[37] E. Pantano and H. Timmermans, "What is Smart for Retailing?," Procedia Environ. Sci., vol. 22, pp. 101-107, 2014.

[38] J. Nazarko et al., "Roadmapping in Regional Technology Foresight: A Contribution to Nanotechnology Development Strategy," IEEE Trans. Eng. Manag., 2020.

[39] Y. R. Li, "The technological roadmap of Cisco's business ecosystem," Technovation, vol. 29, no. 5, pp. 379-386, May 2009.

[40] A. L. Porter and S. W. Cunningham, Tech mining. Exploiting New Technologies for Competitive Advantage. New Jersey, Wiley-Interscience. and S. W. Cunningham, vol. 29. John Wiley \& Sons, 2005.

[41] L. Leydesdorff, The challenge of scientometrics: The development, measurement, and selforganization of scientific communications. Universal-Publishers, 2001.

[42] M. Amer and T. U. Daim, "Application of technology roadmaps for renewable energy sector," Technol. Forecast. Soc. Change, vol. 77, no. 8, pp. 1355-1370, 2010.

[43] T. U. Daim and T. Oliver, "Implementing technology roadmap process in the energy services sector: A case study of a government agency," Technol. Forecast. Soc. Change, vol. 75, no. 5, pp. $687-720,2008$.

[44] W. McDowall, "Technology roadmaps for transition management: The case of hydrogen energy," Technol. Forecast. Soc. Change, vol. 79, no. 3, pp. 530-542, 2012.

[45] S. T. Walsh, R. L. Boylan, C. McDermott, and A. Paulson, "The semiconductor silicon industry roadmap: epochs driven by the dynamics between disruptive technologies and core competencies," Technol. Forecast. Soc. Change, vol. 72, no. 2, pp. 213-236, 2005.

[46] J. Jeon, H. Lee, and Y. Park, "Implementing technology roadmapping with supplier selection for semiconductor manufacturing companies," Technol. Anal. Strateg. Manag., vol. 23, no. 8, pp. 899-918, 2011.

[47] K. Lange, G. Müller-Seitz, J. Sydow, and A. Windeler, "Financing innovations in uncertain networks-Filling in roadmap gaps in the semiconductor industry," Res. Policy, vol. 42, no. 3, pp. 647-661, 2013.

[48] E. Park, A. P. Del Pobil, and S. J. Kwon, "The role of Internet of Things (IoT) in smart cities: Technology roadmap-oriented approaches," Sustainability, vol. 10, no. 5, p. 1388, 2018.

[49] A. J. C. Trappey, C. V Trappey, C.-Y. Fan, A. P. T. Hsu, X.-K. Li, and I. J. Y. Lee, "IoT patent roadmap for smart logistic service provision in the context of Industry 4.0," J. Chinese Inst. Eng., vol. 40, no. 7, pp. 593-602, 2017. 
[50] J. H. Suh and S. C. Park, "Service-oriented technology roadmap (SoTRM) using patent map for R\&D strategy of service industry," Expert Syst. Appl., vol. 36, no. 3, pp. 6754-6772, 2009.

[51] J. H. Lee, R. Phaal, and S. H. Lee, "An integrated service-device-technology roadmap for smart city development," Technol. Forecast. Soc. Change, vol. 80, no. 2, pp. 286-306, 2013.

[52] Y. Geum, S. Lee, D. Kang, and Y. Park, "The customisation framework for roadmapping product-service integration," Serv. Bus., vol. 5, no. 3, p. 213, 2011.

[53] L. Lehtola, M. Kauppinen, and S. Kujala, "Linking the business view to requirements engineering: long-term product planning by roadmapping," in 13th IEEE International Conference on Requirements Engineering (RE'05), 2005, pp. 439-443.

[54] R. Phaal, C. Farrukh, and D. Probert, "Technology Roadmapping: linking technology resources to business objectives," Cent. Technol. Manag. Univ. Cambridge, pp. 1-18, 2001.

[55] D. A. Beeton, R. Phaal, and D. R. Probert, "Exploratory roadmapping for foresight," Int. J. Technol. Intell. Plan., vol. 4, no. 4, pp. 398-412, 2008.

[56] S. G. Behrens, C. Alberts, and R. Ruefle, "Competency lifecycle roadmap: toward Performance readiness," Carnegie-Mellon Univ Pittsburgh Pa Software Engineering Inst, 2012.

[57] I. M. Ilevbare, D. Probert, and R. Phaal, "Towards risk-aware roadmapping: Influencing factors and practical measures," Technovation, vol. 34, no. 8, pp. 399-409, 2014.

[58] M. A. Toro-Jarrín, I. E. Ponce-Jaramillo, and D. Güemes-Castorena, "Methodology for the of building process integration of Business Model Canvas and Technological Roadmap," Technol. Forecast. Soc. Change, vol. 110, pp. 213-225, 2016.

[59] X. Li, Y. Zhou, L. Xue, and L. Huang, "Integrating bibliometrics and roadmapping methods: A case of dye-sensitized solar cell technology-based industry in China," Technol. Forecast. Soc. Change, vol. 97, pp. 205-222, 2015.

[60] S. Lee, B. Yoon, C. Lee, and J. Park, "Business planning based on technological capabilities: Patent analysis for technology-driven roadmapping," Technol. Forecast. Soc. Change, vol. 76, no. 6, pp. 769-786, 2009.

[61] R. Tierney, W. Hermina, and S. Walsh, "The pharmaceutical technology landscape: A new form of technology roadmapping," Technol. Forecast. Soc. Change, vol. 80, no. 2, pp. 194-211, 2013.

[62] H. Martin and T. Daim, "Technology roadmapping through intelligence analysis: case of nanotechnology," Int. J. Soc. Syst. Sci., vol. 1, no. 1, pp. 49-66, 2008.

[63] C. H. Willyard and C. W. McClees, "Motorola's technology roadmap process," Res. Manage., vol. 30, no. 5, pp. 13-19, 1987.

[64] M. Caetano and D. C. Amaral, "Roadmapping for technology push and partnership: A contribution for open innovation environments," Technovation, vol. 31, no. 7, pp. 320-335, 2011.

[65] M. M. Carvalho, A. Fleury, and A. P. Lopes, "An overview of the literature on technology roadmapping (TRM): Contributions and trends," Technol. Forecast. Soc. Change, vol. 80, no. 7, pp. 1418-1437, 2013.

[66] D. Fenwick, T. U. Daim, and N. Gerdsri, "Value Driven Technology Road Mapping (VTRM) process integrating decision making and marketing tools: Case of Internet security technologies," Technol. Forecast. Soc. Change, vol. 76, no. 8, pp. 1055-1077, 2009.

[67] R. Wells, R. Phaal, C. Farrukh, and D. Probert, "Technology roadmapping for a service organization," Res. Manag., vol. 47, no. 2, pp. 46-51, 2004.

[68] E. Pantano, C.-V. V. Priporas, S. Sorace, and G. Iazzolino, "Does innovation-orientation lead to retail industry growth? Empirical evidence from patent analysis," J. Retail. Consum. Serv., vol. 34, pp. 88-94, 2017.

[69] J. Seidler, "On Using Informants: A Technique for Collecting Quantitative Data and Controlling Measurement Error in Organization Analysis," Am. Sociol. Rev., vol. 6, no. 39, pp. 816-831, 1974.

[70] H. Miao, Y. Wang, X. Li, and F. Wu, "Integrating Technology-Relationship-Technology Semantic Analysis and Technology Roadmapping Method: A Case of Elderly Smart Wear Technology," IEEE Trans. Eng. Manag., 2020.

[71] J. M. Gerken, M. G. Moehrle, and L. Walter, "One year ahead! Investigating the time lag between patent publication and market launch: insights from a longitudinal study in the automotive industry," R\&D Manag., vol. 45, no. 3, pp. 287-303, 2015. 
[72] Irena, "Intellectual Property Rights: The Role of Patents in Renewable Energy Technology Innovation," 2013.

[73] E. Mansfield, "Academic research and industrial innovation: An update of empirical findings," Res. Policy, vol. 26, no. 7-8, pp. 773-776, 1998.

[74] G. Napolitano and G. Sirilli, "The patent system and the exploitation of inventions: results of a statistical survey conducted in Italy," Technovation, vol. 10, no. 1, pp. 5-16, 1990.

[75] U. Pora, N. Gerdsri, N. Thawesaengskulthai, and S. Triukose, "Data-Driven Roadmapping (DDRM): Approach and Case Demonstration," IEEE Trans. Eng. Manag., 2020.

[76] O. Saritas and J. E. Smith, "The Big Picture - trends, drivers, wild cards, discontinuities and weak signals," Futures, vol. 43, no. 3, pp. 292-312, 2011.

[77] S. Mendonça, M. P. Cunha, J. Kaivo-oja, and F. Ruff, "Wild cards, weak signals and organisational improvisation," Futures, vol. 36, no. 2, pp. 201-218, 2004.

[78] J. L. Petersen, K. Steinmüller, and H. Adeyema, "10 Wild Cards," Futur. Res. Methodol. v3.0 [CD-ROM], vol. 3, pp. 1-22, 2009.

[79] J. V. Ponomareva and A. Sokolova, "The Identification of Weak Signals and Wild Cards in Foresight Methodology: Stages and Methods," SSRN Electron. J., vol. 46, 2015.

[80] T. U. Daim, G. Rueda, H. Martin, and P. Gerdsri, "Forecasting emerging technologies: Use of bibliometrics and patent analysis," Technol. Forecast. Soc. Change, vol. 73, no. 8, pp. 981-1012, 2006.

[81] S. Ozcan and N. Islam, "Patent information retrieval: approaching a method and analysing nanotechnology patent collaborations," Scientometrics, vol. 111, no. 2, pp. 941-970, 2017.

[82] Y.-H. Tseng, C.-J. Lin, and Y.-I. Lin, "Text mining techniques for patent analysis," Inf. Process. Manag., vol. 43, no. 5, pp. 1216-1247, 2007.

[83] J. Guan and Q. Zhao, "The impact of university-industry collaboration networks on innovation in nanobiopharmaceuticals," Technol. Forecast. Soc. Change, vol. 80, no. 7, pp. 1271-1286, 2013.

[84] A. Porter et al., "Technology futures analysis: Toward integration of the field and new methods," Technol. Forecast. Soc. Change, vol. 71, no. 3, pp. 287-303, Mar. 2004.

[85] I. Rafols and M. Meyer, "How cross-disciplinary is bionanotechnology? Explorations in the specialty of molecular motors," Scientometrics, vol. 70, no. 3, pp. 633-650, 2007.

[86] P. Shapira, J. Youtie, and L. Kay, "National innovation systems and the globalization of nanotechnology innovation," J. Technol. Transf., vol. 36, no. 6, pp. 587-604, 2011.

[87] L. Kay, N. Newman, J. Youtie, A. L. Porter, and I. Rafols, "Patent overlay mapping: Visualizing technological distance," J. Assoc. Inf. Sci. Technol., vol. 65, no. 12, pp. 2432-2443, 2014.

[88] A. L. Porter, A. S. Cohen, J. David Roessner, and M. Perreault, "Measuring researcher interdisciplinarity," Scientometrics, vol. 72, no. 1, pp. 117-147, 2007.

[89] A. L. Porter, J. Youtie, P. Shapira, and D. J. Schoeneck, "Refining Terms for Nanotechnology," J. Nanoparticle, vol. 10, no. 5, pp. 715-728, 2008.

[90] A. L. Porter and I. Rafols, "Is science becoming more interdisciplinary? \nMeasuring and mapping six research fields over time," Scientometrics, vol. 81, no. 3, pp. 719-745, 2009.

[91] L. Leydesdorff and L. Bornmann, "The operationalization of 'fields' as WoS subject categories (WCs) in evaluative bibliometrics: The cases of 'library and information science' and 'science \& technology studies,"” J. Assoc. Inf. Sci. Technol., vol. 67, no. 3, pp. 707-714, 2016.

[92] L. Leydesdorff, D. Kushnir, and I. Rafols, "Interactive overlay maps for US patent (USPTO) data based on International Patent Classification (IPC)," Scientometrics, vol. 98, no. 3, pp. 1583$1599,2014$.

[93] L. Leydesdorff and I. Rafols, "A Global Map of Science Based on the IS Subject Categories," J. Am. Soc. Inf. Sci. Technol., vol. 60, no. 2, pp. 348-362, 2009.

[94] L. Leydesdorff, "Betweenness centrality as an indicator of the interdisciplinary of scientific journals," J. Am. Soc. Inf. Sci. Technol., vol. 58, no. 9, pp. 1303-1319, 2007.

[95] D. F. Iezzi, "Centrality measures for text clustering," Commun. Stat. - Theory Methods, vol. 41, no. 16-17, pp. 3179-3197, 2012.

[96] S. Renko and D. Ficko, "New logistics technologies in improving customer value in retailing service," J. Retail. Consum. Serv., vol. 17, no. 3, pp. 216-223, 2010. 
[97] A. Hübner, H. Kuhn, J. Wollenburg, and A. Trautrims, "From bricks-and-mortar to bricks-andclicks-logistics networks in omni-channel grocery retailing," Empir. Stud. Multi-Channel OmniChannel Retail Oper. Logist., p. 102, 2018.

\section{Appendix A: Summary of the key participants (retail panel experts)}

\begin{tabular}{|c|c|c|c|c|}
\hline $\begin{array}{l}\text { Key } \\
\text { informants } \\
\text { (KI) ID }\end{array}$ & Informant's position & $\begin{array}{l}\text { Size of organisation } \\
\text { (employees) }\end{array}$ & Founded & Type of Organization \\
\hline KI 1 & Sales Manager & 33 & 2010 & Technology Supplier \\
\hline KI 2 & Marketing Manager & 50 & 2003 & Service \& Consultancy Agency \\
\hline KI 3 & Director of Marketing & 90 & 1990 & Technology \& Solution Provider \\
\hline $\mathrm{KI} 4$ & Technology Manager & 500 & 1980 & Online Retailer \\
\hline KI 5 & Retail Analyst & 20 & 2012 & Emerging Markets Researcher \\
\hline KI 6 & Production Manager & 150 & 1988 & Warehousing \& Distributor \\
\hline KI 7 & Service Manager & 250 & 1990 & Online Retailer \\
\hline KI 8 & Production Manager & 120 & 2000 & Manufacturer \\
\hline KI 9 & Store Manager & 70 & 1992 & E-Commerce Analyst \\
\hline KI 10 & Director of Marketing & 350 & 1997 & Distributor \\
\hline KI 11 & Chief Technology Officer & 1200 & 1960 & Multichannel Retailer \\
\hline KI 12 & Retail Sales Director & 600 & 1974 & Wholesaler \\
\hline
\end{tabular}

\section{Appendix B: Patent codes and descriptions}

\begin{tabular}{|c|c|}
\hline Patent codes & Description \\
\hline A45C 3/04 & Shopping Bags; Shopping Nets \\
\hline A47F & $\begin{array}{l}\text { Special Furniture, Fittings, or Accessories For Shops, Storehouses, Bars, Restaurants, or The Like; Paying } \\
\text { Counters }\end{array}$ \\
\hline B25J & $\begin{array}{l}\text { Manipulators; Chambers Provided With Manipulation Devices (Robotic Devices For Individually Picking Fruits, } \\
\text { Vegetables, Hops Etc.) }\end{array}$ \\
\hline B32B 2439/70 & Food Packaging \\
\hline B62B 3/00 & $\begin{array}{l}\text { Hand Carts Having More Than One Axis Carrying Transport Wheels; Steering Devices Therefor; Equipment } \\
\text { Therefor }\end{array}$ \\
\hline B65D & $\begin{array}{l}\text { Containers For Storage or Transport of Articles or Materials, E.G. Bags, Barrels, Bottles, Boxes, Cans, Cartons, } \\
\text { Crates, Drums, Jars, Tanks, Hoppers, Forwarding Containers; Accessories, Closures, or Fittings Therefor; } \\
\text { Packaging Elements; Packages }\end{array}$ \\
\hline B65G 1/00 & Storing Articles, Individually or In Orderly Arrangement, In Warehouses or Magazines \\
\hline G05D 1/00 & Control of Position, Course or Altitude of Land, Water, Air, or Space Vehicles, E.G. Automatic Pilot \\
\hline G06F 17/00 & Digital Computing or Data Processing Equipment or Methods, Specially Adapted For Specific Functions \\
\hline G06F 19/00 & Digital Computing or Data Processing Equipment or Methods, Specially Adapted For Specific Applications \\
\hline G06K & Recognition of Data; Presentation of Data; Record Carriers; Handling Record Carriers \\
\hline G06Q 10/00 & Administration; Management \\
\hline G06Q 20/00 & Payment Architectures, Schemes or Protocols (Apparatus For Performing or Posting Payment Transactions \\
\hline G06Q 30/00 & Commerce, E.G. Shopping or E-commerce \\
\hline G07D & $\begin{array}{l}\text { Handling of Coins or Valuable Papers, E.G. Testing, Sorting By Denominations, Counting, Dispensing, Changing } \\
\text { or Depositing }\end{array}$ \\
\hline G07F & Coin-freed or Like Apparatus \\
\hline G07G & Registering The Receipt of Cash, Valuables, or Tokens \\
\hline G08B 13/00 & Burglar, Theft or Intruder Alarms \\
\hline G09F & Displaying; Advertising; Signs; Labels or Name-plates; Seals \\
\hline H04L & Transmission of Digital Information, E.G. Telegraphic Communication \\
\hline H04M 17/00 & Prepayment \{of Wireline Communication Systems, Wireless Communication Systems \\
\hline H04W & Wireless Communication Networks \\
\hline Y10S 280/03 & Wheeled Shopping Bag \\
\hline Y10S 280/04 & Grocery Store Cart \\
\hline
\end{tabular}

